\title{
Olive-stone biomass ash (OBA): An alternative alkaline source for the blast furnace slag activation
}

\author{
Sayonara Maria de Moraes Pinheiro ${ }^{\mathrm{a}}$, Alba Font ${ }^{\mathrm{b}}$, Lourdes Soriano ${ }^{\mathrm{b}}$, Mauro M. Tashima ${ }^{\mathrm{c}}$, José Monzó ${ }^{\mathrm{b}}$, \\ Maria Victoria Borrachero ${ }^{\mathrm{b}}$, Jordi Payá ${ }^{\mathrm{b}, *}$ \\ ${ }^{a}$ UFES - Federal University of Espírito Santo, Department of Civil Engineering, Brazil \\ b ICITECH - GIQUIMA Group - Grupo de Investigación en Química de los Materiales de Construcción, Instituto de Ciencia y Tecnología del Hormigón, Universitat Politècnica \\ de Valencia, Valencia, Spain \\ ${ }^{\mathrm{c}}$ UNESP - Grupo de Pesquisa MAC - Materiais Alternativos de Construção, Universidade Estadual Paulista, Campus de Ilha Solteira, São Paulo, Brazil
}

\section{H I G H L I G H T S}

- Olive-stone biomass ash (OBA) was successfully tested as activator.

- OBA has alkaline properties suitable for alkali activated materials (AAM).

- OBA was used as unique activator for blast furnace slag (BFS).

- The effectivity of OBA was higher than $\mathrm{KOH}$ and similar to $\mathrm{NaOH}$.

- OBA reduces the consumption of commercial chemical reagents in AAM.

\section{A R T I C L E I N F O}

Article history:

Received 28 February 2018

Received in revised form 24 April 2018

Accepted 19 May 2018

Available online 26 May 2018

\section{Keywords:}

Conservation

Alkali activated material

Blast furnace slag

Olive-stone biomass ash

Strength development

\begin{abstract}
A B S T R A C T
Alkali activated materials (AAM) are being investigated as an alternative binder that could be more eco-efficient than Portland cement. The effect of olive-stone biomass ash (OBA) on the activation of blast furnace slag (BFS) was studied. The mechanical behaviour of mortars in which OBA was replaced, or added to, BFS were compared to those found for BFS mortars activated with potassium hydroxide $(\mathrm{KOH})$ and sodium hydroxide $(\mathrm{NaOH})$ solutions in the range of $4-12 \mathrm{~mol} \cdot \mathrm{kg}^{-1}$. The results showed the high efficiency of OBA as activating reagent because it provided similar, or higher, strengths when compared to the alkali hydroxide activating solutions. The microstructural characteristics of the new binding OBA/BFS systems were assessed by X-ray diffraction (XRD), thermogravimetric analysis (TGA), field emission scanning electron microscopy (FESEM) and mercury intrusion porosimetry (MIP). These systems showed lower mean pore diameter and scarcer formation of zeolite structures when compared to $\mathrm{KOH} / \mathrm{BFS}$ systems. These promising results demonstrated the viability of the use of these type of ashes as activating reagents in AAM.
\end{abstract}

(c) 2018 Elsevier Ltd. All rights reserved.

\section{Introduction}

Currently, cementing materials resulting from alkaline activation of alumino-silicate precursors are becoming a well-known alternative to Portland cement. They are overcoming the limitations of Portland cement in terms of mechanical and durability performance, and also minimize environmental impacts, such as $\mathrm{CO}_{2}$ emissions and energy consumption [1]. These materials are denominated as alkali-activated materials (AAM) or geopolymers [2-4].

\footnotetext{
* Corresponding author.

E-mail address: jjpaya@cst.upv.es (J. Payá).
}

In general, the raw materials used as source of alumino-silicates are blast furnace slag (BFS) [5,6], metakaolin [7] or fly ash [8,9]. In the last few years, some industrial and agricultural wastes have been investigated, and some of them have shown the ability for alkali-activated procedures in simple or combined systems, such as fluid catalytic cracking catalyst FCC residue [10], ceramic waste [11,12], bottom coal ash [13] and sugarcane waste-derived ash [14], among others.

However, there are fewer examples in which wastes have been used in the preparation of the activating solution. This is a critical subject, because the environmental impact relates to its synthesis. The commercial reagents for preparing solutions used to activate the precursor are produced with natural raw materials and involve 
industrial processes with high energy costs and high $\mathrm{CO}_{2}$ emission, especially the alkali silicates $[15,16]$.

In order to minimize this impact, several studies have been done [15-20]. Gao et al. [15] reported the use of nanosilica from olivine for preparing alkali activating reagents for the activation of slag-fly ash blends. In some cases, the goal was to supply soluble silicate by dissolution of the rice husk ash [16-20]. The reagent for producing the dissolution was commercial sodium hydroxide, and the results indicated the feasibility of its use. However, very few studies were reported in which AAM was prepared with raw materials (precursor and activating solution) and were derived exclusively from waste (100\%-waste AAM).

Recently, an alkaline sodium hydroxide waste solution from an aluminium cleaning mould process was studied [21]. In this study, the waste was used to supply the alkali activating solution on different precursors, and the results were promising for its use in the industry of geopolymers.

In this context, olive-stone biomass ash (OBA) comes up as a promising alkali source for preparation of AAMs. It has a significant amount of potassium and when mixed with BFS, showed promising properties, such as compressive and flexural strengths of the mortar [22]. Also, ashes from maize stalk and maize cob were used for activating metakaolin [23].

During the production of olive oil, two types of waste are generated, a liquid (waste water) and a solid phase (Fig. 1). The liquid phase, "alpechín" (wastewater from olive oil mills), contains a large number of solid residues, oil, grease and polyphenols. It is a highly contaminant material [24-27] because of its acidity and high chemical (DQO) and biochemical (DQO) oxygen demands. The solid waste (SW) phase is a paste formed by a mixture of pulp, bark, olive stone and residual oil, called "orujo", "alpeorujo", "orujillo" or "cake". This SW has a high concentration of organic matter, oil and grease, and is rich in calcium and potassium [28-30]. It is a contaminant material, has a strong smell and high moisture content. It can be used as an energy resource, such as for biofuel, animal feed and soil fertilizer [24,31,32].
The amount of the SW and its physical-chemical characteristics depend on the production process used for the oil extraction. It has been estimated that in $1000 \mathrm{~kg}$ of olive oil production, 1500-4000 $\mathrm{kg}$ of SW are generated. In addition to the type of process, changes in yield and contamination of the waste can occur [29,30,32,33].

The world production of olive oil expected for 2016/2017 is estimated to be $2.7 \mathrm{Mt}$, and $92 \%$ will be produced in the Mediterranean area and $48.3 \%$ in Spain [34]. Considering the average residue generation rate, where solid waste/olive oil $=2.5$, it is possible to expect the generation of 4.9 Mt of SW in Spain.

To be used as a biofuel, the SW must be dried. In addition, the stone can be segregated to generate a by-product with a higher calorific value about $4490 \mathrm{kcal} / \mathrm{kg}$ [35]. The combustion of these solid waste phases generates ashes (Fig. 1): a general olive waste ash (OWA) and a specific olive-stone biomass ash (OBA) [25]. The chemical characteristics of these ashes depend on many factors, such as SW composition, combustion temperature and the presence of contaminants (Table 1 ). The estimated amount of ash generated in the burning process from dried SW is about $12 \%$ by mass [36].

The reuse of these ashes in the preparation of concrete and mortars has been widely reported [36-39]. The studies with OWA were done with concrete and mortars, using it as a replacement material for Portland cement, fine filler material and sand [36-39].

Specifically, Eisa [39] found a reduction in the compressive and flexural strengths of concrete when OWA was used as a replacement for Portland cement. Al-Akhras et al. [36], obtained a more durable material at high temperatures when OWA was used as a replacement for Portland cement. It was also more resistant to the alkali-silica reaction, when OWA was used as a replacement for sand [38]. The authors explained the improvement in the performance of the material due to a possible pozzolanic and filler effects of OWA.

Al-Akhras and Abdulwahid [37] used OWA as a replacement for Portland cement and sand in mortars. The mortars they produced showed a decrease in the workability with the increase of OWA

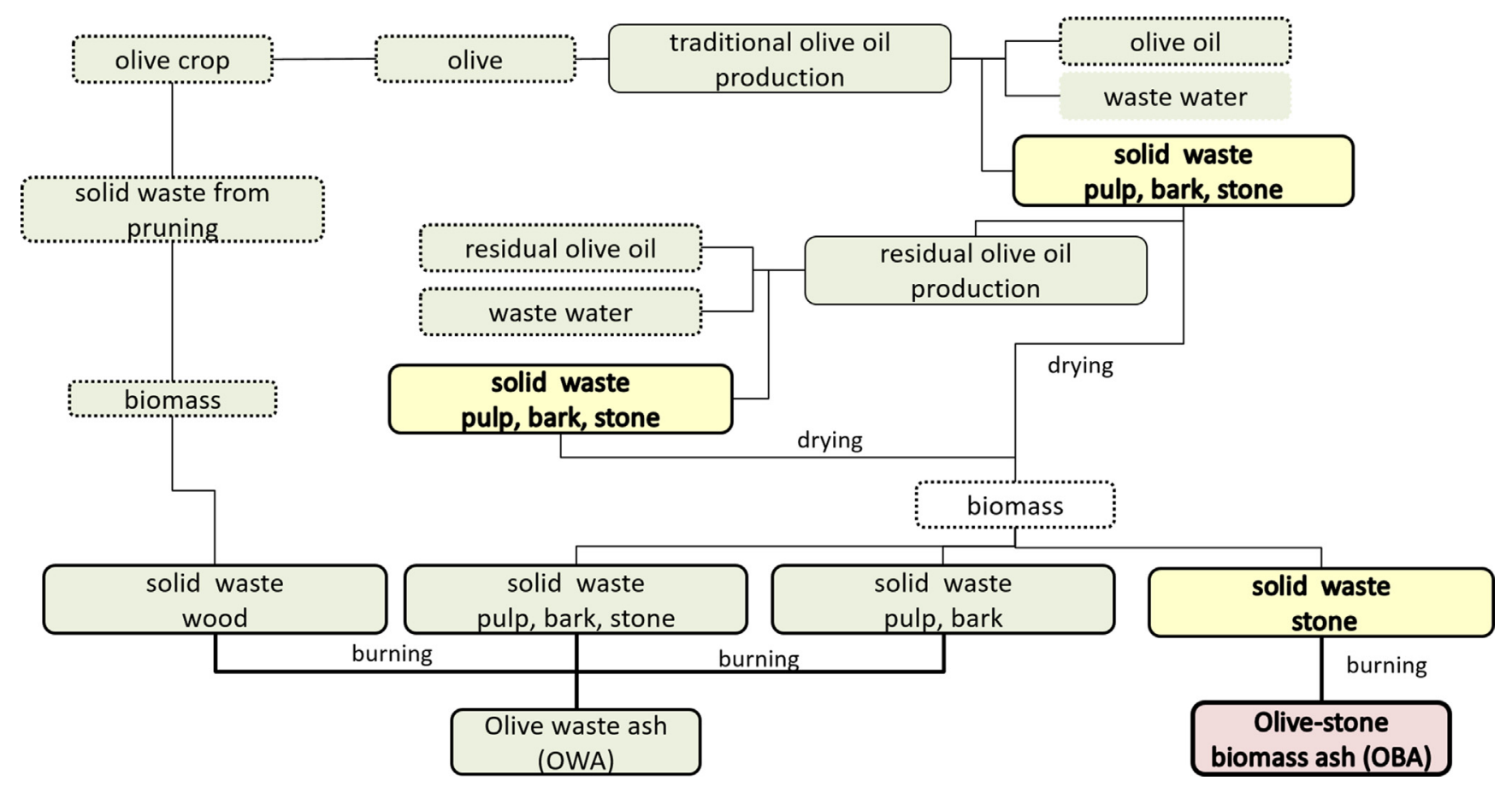

Fig. 1. Scheme of the production of olive oils, generation of wastes and their ashes by combustion. 
Table 1

Reported chemical compositions for OWA and OBA.

\begin{tabular}{|c|c|c|c|c|c|c|c|c|c|c|c|}
\hline Waste & $\mathrm{SiO}_{2}$ & $\mathrm{CaO}$ & $\mathrm{Al}_{2} \mathrm{O}_{3}$ & $\mathrm{Fe}_{2} \mathrm{O}_{3}$ & $\mathrm{Na}_{2} \mathrm{O}$ & $\mathrm{K}_{2} \mathrm{O}$ & $\mathrm{MgO}$ & $\mathrm{P}_{2} \mathrm{O}_{5}$ & $\mathrm{SO}_{3}$ & LOI & REF \\
\hline \multirow[t]{6}{*}{ OWA - wood } & 2.70 & 52.30 & 1.40 & 2.10 & 0.10 & 1.50 & 2.70 & 1.50 & 2.60 & 32.06 & [35] \\
\hline & 8.10 & 32.80 & 1.60 & 0.70 & 2.90 & 19.90 & 2.40 & 8.50 & 2.10 & 20.90 & [35] \\
\hline & 9.20 & 43.40 & 1.50 & 1.90 & 2.70 & 12.70 & 2.80 & 12.70 & 1.70 & 11.20 & [35] \\
\hline & 10.00 & 44.20 & 1.20 & 1.00 & 2.60 & 7.20 & 3.50 & 17.00 & 6.80 & 6.40 & [35] \\
\hline & 10.24 & 41.47 & 2.02 & 0.88 & 3.67 & 25.16 & 3.03 & 10.75 & 2.65 & - & [41] \\
\hline & 11.84 & 54.82 & 2.60 & 1.38 & 0.16 & 9.26 & 4.36 & 3.40 & - & 11.73 & [42] \\
\hline OWA - bark & 32.70 & 14.50 & 8.40 & 6.30 & 26.20 & 4.30 & 4.20 & 2.50 & 0.60 & - & [43] \\
\hline \multirow[t]{2}{*}{ OWA - pulp, bark and stone } & 22.26 & 12.93 & 4.10 & 1.99 & 0.12 & 42.79 & 5.84 & 6.09 & 3.73 & - & {$[41]$} \\
\hline & 33.00 & 18.14 & 16.66 & 6.50 & 2.50 & 11.20 & 10.00 & - & 2.93 & 3.52 & [40] \\
\hline \multirow[t]{3}{*}{ OWA - pulp and bark } & 25.30 & 42.40 & 7.40 & 4.60 & 0.45 & 3.30 & 3.20 & - & 3.70 & 9.50 & [36] \\
\hline & 25.80 & 42.90 & 8.50 & 5.70 & 0.25 & 0.33 & 3.20 & - & 3.80 & 9.50 & [37] \\
\hline & 25.80 & 42.90 & 8.50 & 5.70 & 0.25 & 0.33 & 3.20 & - & 3.80 & 9.50 & [38] \\
\hline \multirow[t]{7}{*}{ OBA - stone } & 31.47 & 13.66 & 6.45 & 6.97 & 27.43 & 1.77 & 4.48 & 33.33 & 1.98 & - & [44] \\
\hline & 21.40 & 33.00 & 4.40 & 7.90 & 0.60 & 2.70 & 3.70 & 2.30 & 4.40 & 18.70 & [35] \\
\hline & 10.70 & 22.00 & 2.70 & 1.70 & 3.40 & 24.70 & 3.00 & 14.70 & 3.50 & 13.30 & [35] \\
\hline & 15.00 & 28.70 & 3.10 & 2.30 & 4.10 & 19.90 & 4.20 & 11.60 & 2.50 & 8.30 & [35] \\
\hline & 20.40 & 32.90 & 4.40 & 2.60 & 4.30 & 12.70 & 4.80 & 11.10 & 4.80 & 1.50 & [35] \\
\hline & 21.48 & 19.97 & 5.95 & 4.25 & 15.77 & 16.44 & 3.84 & 9.71 & 2.30 & - & [41] \\
\hline & 5.33 & 27.77 & 0.70 & 3.45 & 0.78 & 32.12 & 5.13 & 2.68 & 1.67 & 18.90 & [22] \\
\hline
\end{tabular}

content. Also, they observed an increase in the compressive and flexural strengths when sand was replaced with OWA, and a decrease when Portland cement was replaced by it. Cruz-Yusta et al. [40] analysed the effect of OWA as a replacement for Portland cement and as a filler material. The authors concluded that a replacement of up to $10 \%$ of Portland cement is feasible without major changes in strength, and showed a low pozzolanic activity of the material, as well as its filler effect.

The first study of OBA was carried out by Font et al. [22]. The ash was characterized and it showed a high amount of $\mathrm{K}_{2} \mathrm{O}$ (32.16\%) and $\mathrm{CaO}$ (27.77\%). They also noted the high alkalinity in water suspension $(\mathrm{pH}=13.5)$ and the presence of crystalline phases, such as portlandite, calcite, anorthite and kalicinite. These characteristics show that the material can be a potential source of alkalis in AAMs. In this first study, the potential of OBA in alkaline activation was assessed in BFS mortars and three types of mixtures (BFS/water, BFS/KOH and BFS/OBA). The results showed: a) the BFS was alkali activated by the OBA, b) the AAM matrix produced with OBA was stronger than the matrix produced with $\mathrm{KOH}$ and c) a filler effect in the matrix was observed.

To better understand of the behaviour of OBA in AAM, this study analysed the binary system composed by blast furnace slag (BFS) and olive-stone biomass ash (OBA) to evaluate the alkaline reactive potential of OBA. A comparison in mechanical behaviour and microstructural parameters was carried out in order to assess the role of OBA, and the effect of the percentage of OBA, in the prepared BFS-based mixtures.

\section{Materials and methods}

\subsection{Materials}

The materials used in this experiment were blast furnace slag (BFS), olive-stone biomass ash (OBA), kephalite (KPH), potassium hydroxide $(\mathrm{KOH})$ and sodium hydroxide $(\mathrm{NaOH})$.

Blast furnace slag (BFS) was used as a precursor in all mixtures. It was supplied by Cementval (Puerto de Sagunto, Valencia, Spain). The particle size distribution is shown in Fig. 2. It had $26.0 \mu \mathrm{m}$ mean particle diameter and its chemical composition is summarized in Table 2.

Olive-stone biomass ash (OBA) was supplied by Almazara Candela - Elche, Spain. It was produced in the combustion of olivestone to produce heat. The resulting ash was collected from the bottom of the furnace. The received sample was dried at $105{ }^{\circ} \mathrm{C}$ for $24 \mathrm{~h}$ and was immediately ground into a ball mill in order to homogenize the material, increase its fineness and improve its dissolution rate in water. It presented $27.4 \mu \mathrm{m}$ mean particle diameter, and the particle size distribution is shown in Fig. 2. Its chemical composition is summarized in Table 2. The XRD pattern showed the main crystalline phases (Fig. 3 ) as portlandite $\left(\mathrm{Ca}\left(\mathrm{OH}_{2}\right), \mathrm{PDF}\right.$ card 040733), calcite $\left(\mathrm{CaCO}_{3}, \mathrm{PDF}\right.$ card 050586), anorthite $\left(\mathrm{CaAl}_{2} \mathrm{Si}_{2} \mathrm{O}_{8}\right.$, PDF card 411486) and kalinicite $\left(\mathrm{KHCO}_{3}\right.$, PDF card 120292). Also, quartz $\left(\mathrm{SiO}_{2}\right.$, PDF card 331161), silvite ( $\mathrm{KCl}, \mathrm{PDF}$ card 411476) and gismondine $\left(\mathrm{CaAl}_{2} \mathrm{Si}_{2} \mathrm{O}_{8} \cdot 4 \mathrm{H}_{2} \mathrm{O}, \mathrm{PDF}\right.$ card 200452) were detected. The size and shape of ground OBA particles are depicted in Fig. 4. In general, OBA particles were porous and irregular, and some particles presented a smooth surface (these were identified as unburned olive-stone particles).

Kephalite (KPH) is a pure crystalline andalucite $\left(\mathrm{Al}_{2} \mathrm{SiO}_{5}, 63 \%\right.$ in $\mathrm{Al}_{2} \mathrm{O}_{3}$ and $37 \%$ in $\mathrm{SiO}_{2}$ by weight) which is used as inert material because of its low solubility in an alkaline medium (the solubility in boiling $4 \mathrm{M} \mathrm{KOH}$ solution for $4 \mathrm{~h}$ was less than $5 \%$ ). The particle size distribution is shown in Fig. 2, and its mean particle diameter was $31.1 \mu \mathrm{m}$.

Commercial potassium hydroxide $(\mathrm{KOH}, 85 \%$ purity, pellets) and sodium hydroxide ( $\mathrm{NaOH}, 98 \%$ purity, pellets) were supplied by Panreac S.A.

\subsection{Methods}

The methodology applied to evaluate the reactive potential of OBA, as an alkaline source to activate BFS, included the analysis of mechanical properties and microstructural characteristics obtained in mortars and pastes. Alkali activated samples were produced with different mass ratios of BFS/OBA. The control mortars and pastes were produced with $\mathrm{BFS} / \mathrm{KOH}, \mathrm{BFS} / \mathrm{NaOH}$ and $\mathrm{BFS} /$ $\mathrm{KOH}+\mathrm{KPH}$.

Mortars were prepared with $\mathrm{w} / \mathrm{b}=0.4$ (water/binder, being the binder the quantity of BFS in control mortars) and $a / b=3$ (aggregate/binder) ratios. The fresh mixture was poured in three prismatic $40 \times 40 \times 160 \mathrm{~mm}^{3}$ moulds and they were demoulded after $4 \mathrm{~h}$ in a thermal bath $\left(65^{\circ} \mathrm{C}\right)$. The specimens were cured for 7 days at $65^{\circ} \mathrm{C}$. Three values for flexural strength (Rf) and six values for compressive strength (Rc) were obtained for each mixture according to UNE 196-1 [45].

Alkaline activation of BFS was assessed by a family of mortars produced with $\mathrm{BFS} / \mathrm{KOH}$ and $\mathrm{BFS} / \mathrm{NaOH}$ in different concentrations. These mortars were noted as BFS/KOH-xM and BFS/NaOH-xM, 


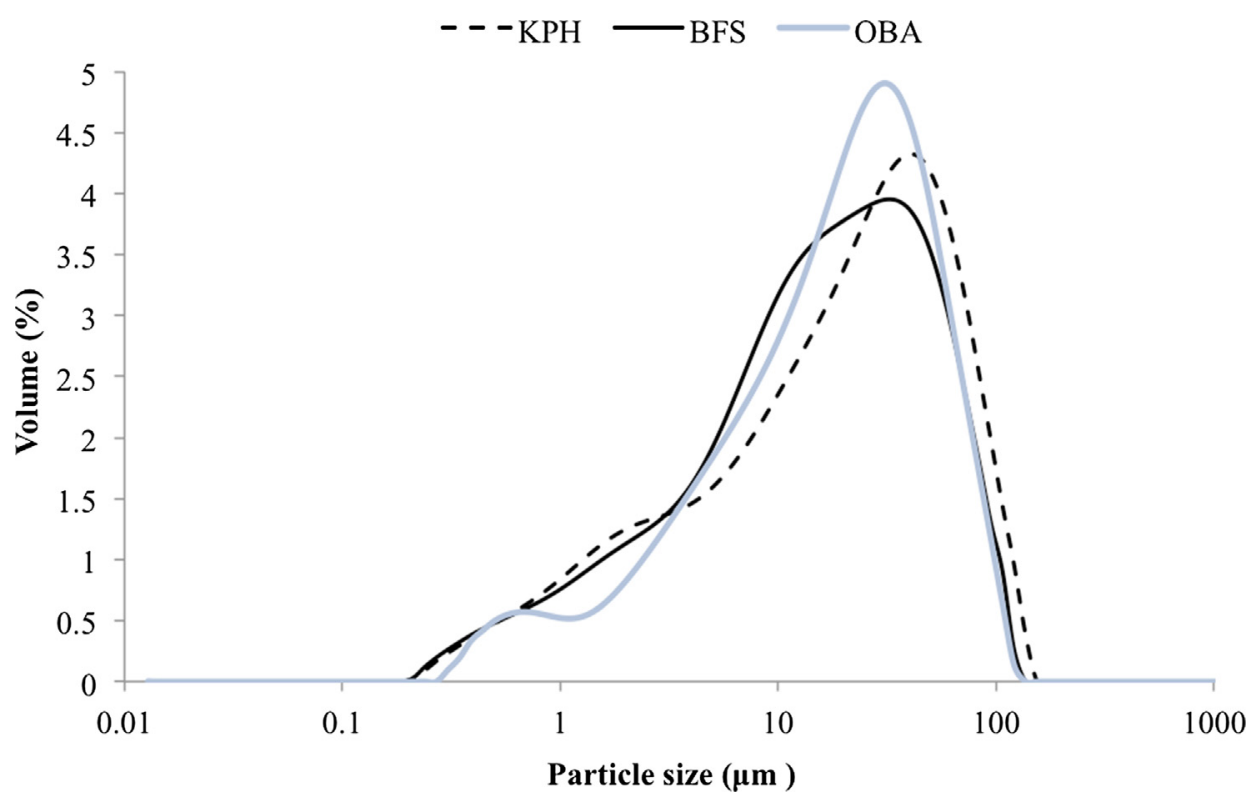

Fig. 2. Particle size distribution curves for BFS, OBA and KPH.

Table 2

Chemical compositions for BFS and OBA.

\begin{tabular}{|c|c|c|c|c|c|c|c|c|c|c|c|}
\hline \multirow[t]{2}{*}{ Materials } & \multicolumn{11}{|c|}{ Oxide composition (\%) } \\
\hline & $\mathrm{SiO}_{2}$ & $\mathrm{CaO}$ & $\mathrm{Al}_{2} \mathrm{O}_{3}$ & $\mathrm{Fe}_{2} \mathrm{O}_{3}$ & $\mathrm{Na}_{2} \mathrm{O}$ & $\mathrm{MgO}$ & $\mathrm{K}_{2} \mathrm{O}$ & $\mathrm{P}_{2} \mathrm{O}_{5}$ & $\mathrm{SO}_{3}$ & others & LOI \\
\hline BFS & 30.53 & 40.15 & 10.55 & 1.29 & 0.87 & 7.43 & 0.57 & 0.26 & 1.93 & 0.89 & 5.53 \\
\hline OBA & 5.33 & 27.77 & 0.70 & 3.45 & 0.78 & 5.13 & 32.12 & 2.68 & 1.67 & 0.95 & 18.90 \\
\hline
\end{tabular}

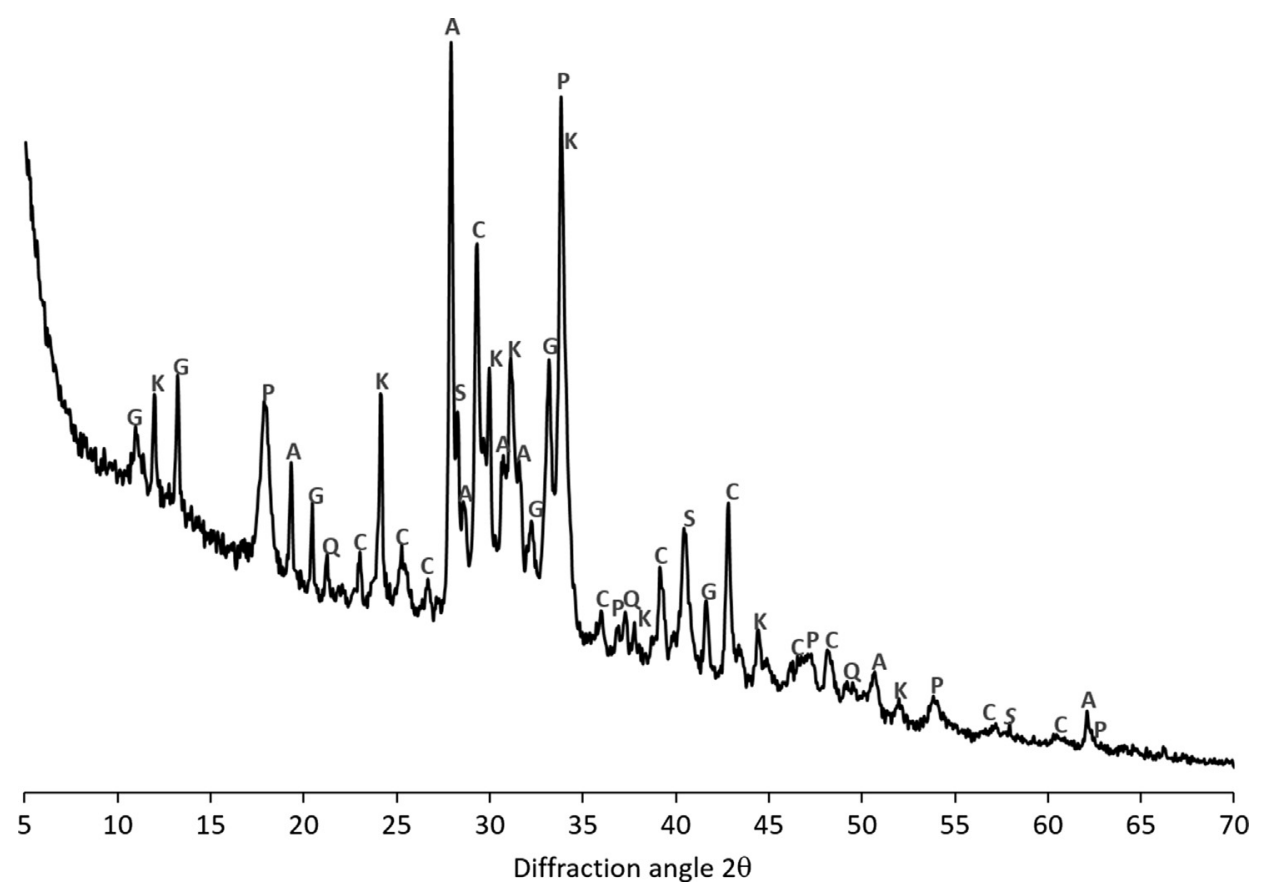

Fig. 3. X-ray diffraction pattern of OBA (Key: P, portlandite; C, calcite; A, anorthite; K, kalinicite; Q, quartz; S, silvite; G, gismondine).

where " $\mathrm{x}$ " is the molality $\left(\mathrm{mol} \cdot \mathrm{kg}^{-1}\right)$ value of the alkaline solution $\left(\mathrm{x}=4,6,8,10,12\right.$ and $14 \mathrm{~mol} \cdot \mathrm{kg}^{-1}$; the symbol $\mathrm{M}$ will be used in the manuscript for simplicity).

The filler effect was controlled by means of mortars produced with $\mathrm{BFS} / \mathrm{KOH}+\mathrm{KPH}$. Two types of mortars with $4 \mathrm{M} \mathrm{KOH}$ were synthetized, one with KPH 20\% addition (Ad) respect to BFS and the other with $20 \%$ replacement (Rp) of the BFS. They were named as KPH-Ad20-4M and KPH-Rp20-4M, respectively.

BFS/OBA mortars were produced by blending both solids. An addition series (Ad) was prepared, where a given percentage of 

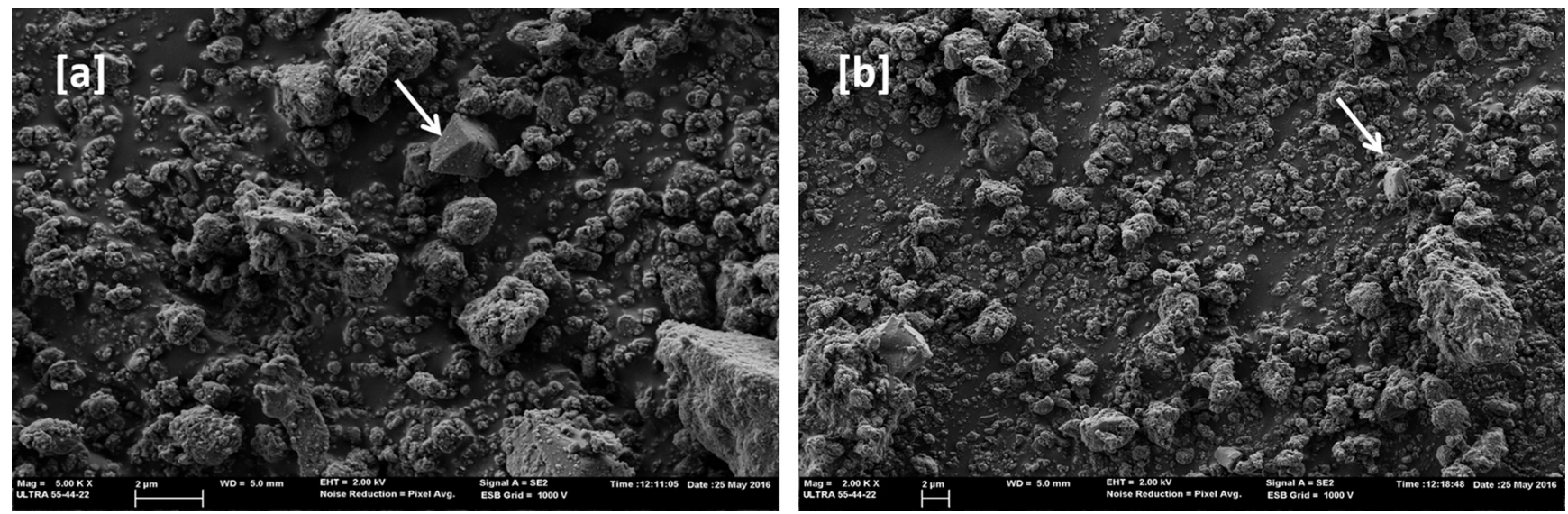

Fig. 4. FESEM micrographs for OBA: a) $5000 \times$; b) $2000 \times$. Arrows indicate the presence of unburned olive-stone particles.

OBA was added by mass with respect to BFS content, and a replacement series (Rp) was prepared by the substitution by mass of BFS by OBA. They were named as OBA-Ady and OBA-Rpz respectively, where " $y$ " is the addition content of OBA ( $y=5,10,15,20$ and 25\%) and " $\mathrm{z}$ " is the replacement by OBA ( $\mathrm{z}=15,20,25,30$ and $35 \%)$.

The pastes used in these analyses were prepared with $\mathrm{w} / \mathrm{b}=0.4$ and were moulded in a plastic container, sealed and cured for 7 days at $65^{\circ} \mathrm{C}$. The microstructure of the hydrated products in the pastes was evaluated by: a) powder X-ray diffraction (XRD), carried out by a Bruker AXS D8 Advance, from $10^{\circ}$ to $70^{\circ} 2 \theta$, and with $\mathrm{Cu} \mathrm{K} \alpha$ radiation at $40 \mathrm{kV}$ and $20 \mathrm{~mA}$; b) thermogravimetric analysis (TG/DTG), using a TGA850 Mettler Toledo thermobalance with a temperature range of $35-600{ }^{\circ} \mathrm{C}$, heating rate of $10^{\circ} \mathrm{C} \mathrm{min}-1$ in an $\mathrm{N}_{2}$ atmosphere with $75 \mathrm{~mL} \cdot \mathrm{min}^{-1}$ gas flow; c) field emission scanning electron microscopy (FESEM) by an ULTRA 55-ZEISS (the powdered sample of OBA was not covered by any material and the pastes were covered by carbon) and EDS with 6-8 mm work distance and extra high voltage of $20 \mathrm{kV}$; and d) mercury intrusion porosimetry (MIP) by means of an AutoPore IV 9500 by the Micromeritics Instrument Corporation, that measured pores in the range of $91.26 \mu \mathrm{m}-5.5 \mathrm{~nm}$.

For TG/DTG and XRD, 5 types of pastes were analysed: $\mathrm{P}-\mathrm{BFS} / \mathrm{KOH}-\mathrm{xM}(\mathrm{x}=4$ and $8 \mathrm{M}), \mathrm{P}-\mathrm{OBA}-\mathrm{Adx}(\mathrm{x}=20$ and $25 \%)$ and P-KPH-Ad20-4M. For FESEM and porosity studies, 4 types of pastes were analysed: P-BFS/KOH-xM $(\mathrm{x}=4,8 \mathrm{M})$ and P-OBA-Adx $(\mathrm{x}=10$ and 25\%).

\section{Results and discussion}

\subsection{BFS activated by $\mathrm{KOH}$ and $\mathrm{NaOH}$}

The effect of $\mathrm{KOH}$ and $\mathrm{NaOH}$ solutions on the hydration of BFS was evaluated by the mechanical and microstructural performance of mortars and pastes. Samples were prepared by means of alkali activating solutions with different concentrations of $\mathrm{KOH}$ and $\mathrm{NaOH}$. The mechanical properties evaluated in mortars included the compressive (Rc) and flexural (Rf) strengths. In Table 3, the mechanical properties are summarized, while in Figs. 5 and 6 a comparison of the compressive and flexural strengths of the mortars is shown respectively.

The $\mathrm{KOH}$ series showed a nonlinear behaviour with alkali concentration and a maximum Rc value was found for $[\mathrm{KOH}]$ equal to $8 \mathrm{M}$. For this mixture, the Rc value reached $25.56 \mathrm{MPa}$. The lowest values were found for $[\mathrm{KOH}]$ equal to $4 \mathrm{M}$ and $14 \mathrm{M}$ (in the 14-15 MPa range), whereas Rc values in the range 19-21 $\mathrm{MPa}$ were obtained for the rest of the $\mathrm{KOH}$ mortars. A similar trend
Table 3

Mechanical properties (compressive, Rc; flexural, Rf) of mortars cured for 7 days at $65^{\circ} \mathrm{C}$.

\begin{tabular}{lll}
\hline Mortars & \multicolumn{2}{l}{ Mechanical properties } \\
\cline { 2 - 3 } & Rc $(\mathrm{MPa})$ & $\mathrm{Rf}(\mathrm{MPa})$ \\
\hline BFS/KOH-4M & $14.55 \pm 0.70$ & $3.38 \pm 0.15$ \\
BFS/KOH-6M & $20.31 \pm 0.32$ & $3.90 \pm 0.02$ \\
BFS/KOH-8M & $25.56 \pm 0.73$ & $3.73 \pm 0.53$ \\
BFS/KOH-10M & $20.77 \pm 0.64$ & $2.32 \pm 0.18$ \\
BFS/KOH-12M & $19.31 \pm 0.67$ & $2.35 \pm 0.14$ \\
BFS/KOH-14M & $14.94 \pm 0.66$ & $1.79 \pm 0.07$ \\
BFS/NaOH-4M & $17.57 \pm 0.59$ & $3.95 \pm 0.34$ \\
BFS/NaOH-6M & $24.07 \pm 0.38$ & $5.64 \pm 0.25$ \\
BFS/NaOH-8M & $26.90 \pm 0.67$ & $5.82 \pm 0.71$ \\
BFS/NaOH-10M & $27.90 \pm 0.64$ & $4.35 \pm 0.36$ \\
BFS/NaOH-12M & $31.11 \pm 1.46$ & $6.06 \pm 0.30$ \\
BFS/NaOH-14M & $26.04 \pm 0.79$ & $5.12 \pm 0.57$ \\
KPH-Ad20-4M & $15.31 \pm 0.60$ & $3.80 \pm 0.35$ \\
KPH-Rp20-4M & $11.88 \pm 0.54$ & $3.41 \pm 0.09$ \\
OBA-Rp15 & $16.27 \pm 0.72$ & $3.14 \pm 0.05$ \\
OBA-Rp20 & $26.01 \pm 0.81$ & $6.47 \pm 0.55$ \\
OBA-Rp25 & $29.42 \pm 1.01$ & $6.30 \pm 0.16$ \\
OBA-Rp30 & $31.25 \pm 1.00$ & $6.04 \pm 0.35$ \\
OBA-Rp35 & $27.81 \pm 0.33$ & $5.76 \pm 0.16$ \\
OBA-Ad5 & $8.59 \pm 0.25$ & $2.64 \pm 0.09$ \\
OBA-Ad10 & $16.13 \pm 0.22$ & $3.85 \pm 0.23$ \\
OBA-Ad15 & $21.47 \pm 0.61$ & $3.47 \pm 0.47$ \\
OBA-Ad20 & $34.74 \pm 1.51$ & $6.88 \pm 0.62$ \\
OBA-Ad25 & $38.38 \pm 1.29$ &
\end{tabular}

was found for Rf, where the highest strength value of 3.90 MPa was obtained for $[\mathrm{KOH}]$ equal to $6 \mathrm{M}$.

The $\mathrm{NaOH}$ series showed similar behaviour to the $\mathrm{KOH}$ series. The Rc values increased for $[\mathrm{NaOH}]=12 \mathrm{M}$ and decreased for $[\mathrm{NaOH}]=14 \mathrm{M}$. The maximum value was $31.11 \mathrm{MPa}$, and the lowest was $17.57 \mathrm{MPa}$. For Rf, the trend was the same, as it increased from $3.95 \mathrm{MPa}$ for $[\mathrm{NaOH}]=4 \mathrm{M}$ to $6.05 \mathrm{MPa}$ for $[\mathrm{NaOH}]=12 \mathrm{M}$, and decreased to $5.12 \mathrm{MPa}$ for $[\mathrm{NaOH}]=14 \mathrm{M}$. In general, the strengths for the sodium series were slightly higher than for $\mathrm{KOH}$ series. Taking into account the chemical nature of OBA, which was richer in $\mathrm{K}_{2} \mathrm{O}$ than in $\mathrm{Na}_{2} \mathrm{O}$, the systems prepared with OBA may be initially compared to those obtained with $\mathrm{KOH}$, although comparisons will be done also to the $\mathrm{NaOH}$ series, to assess the equivalency among the ash and the commercial alkaline reagents.

By means of the MIP data on the corresponding pastes (Table 4), it was possible to observe the reduction in the porosity with the increase of the $\mathrm{KOH}$ concentration, from $47.16 \%$ (P-BFS/KOH-4M) to $23.74 \%$ (P-BFS/KOH-8M), as well as the reduction of mean pore 


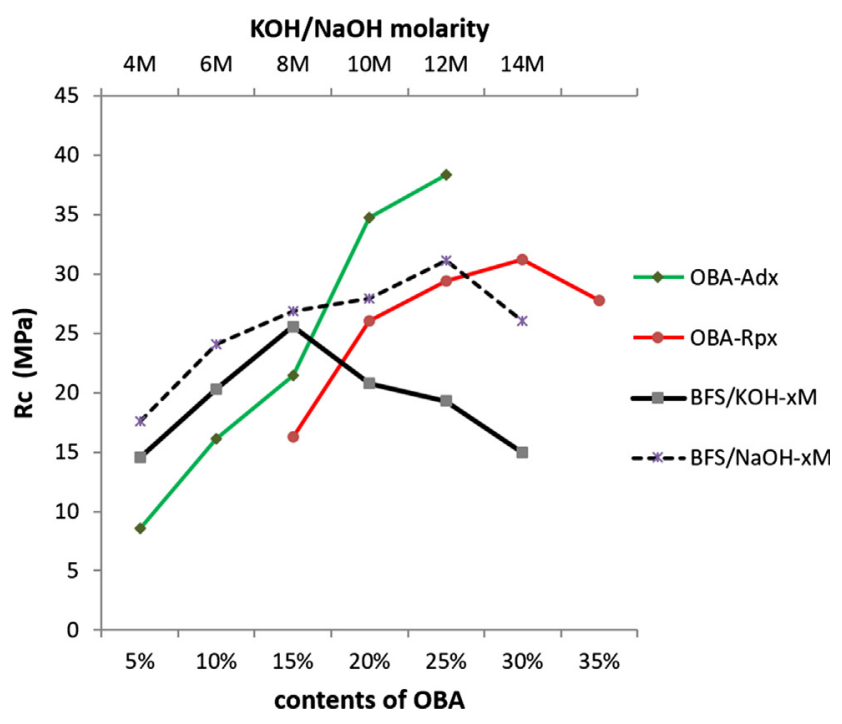

Fig. 5. Compressive strength behaviour of mortars.

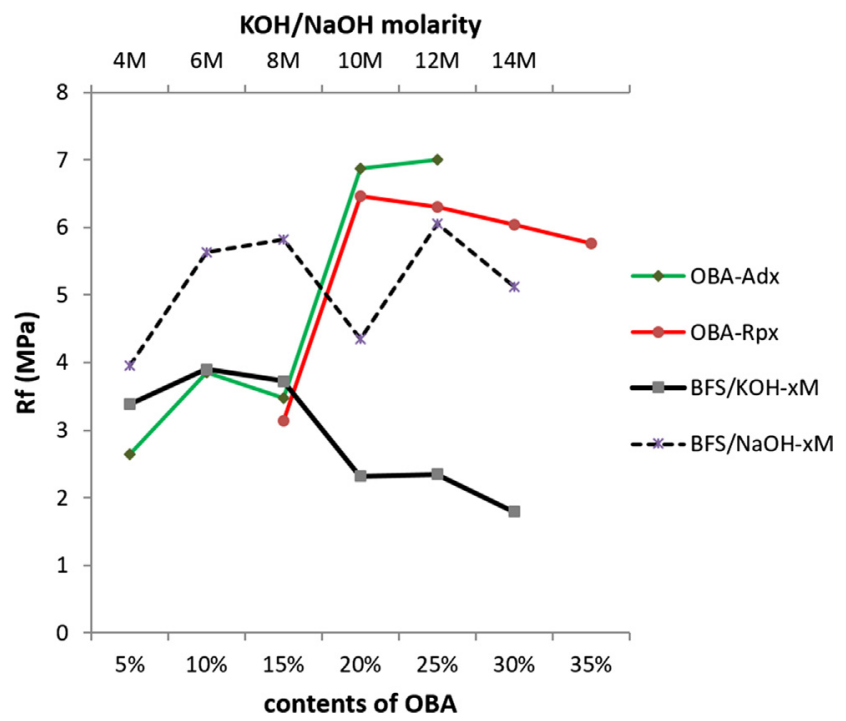

Fig. 6. Flexural strength behaviour of mortars.

diameter (from $48.2 \mathrm{~nm}$ to $22.9 \mathrm{~nm}$ ). These characteristics confirmed the refinement of the pore network, showing the increase in the compactness for P-BFS/KOH-8M, and consequently the higher mechanical strength [46].

Thermal analysis (TG/DTG) for the $\mathrm{KOH}$ family registered several mass loss events in the $35-600{ }^{\circ} \mathrm{C}$ range (Table 5 and Fig. 7). The first one occurred around $140{ }^{\circ} \mathrm{C}$ and indicated the loss of combined water from the main hydrated products, C-S-H and (C,K)-S$\mathrm{H}$. The second event showed two peaks in the DTG curve at 200 ${ }^{\circ} \mathrm{C}$ and in the $238-259{ }^{\circ} \mathrm{C}$ range, which were related to dehydration of C-A-S-H and (C,K)-A-S-H. The third peak, at about $390^{\circ} \mathrm{C}$, was associated to the presence of hydrotalcite. Similar results were reported by other researchers $[8,47,48]$. The total mass loss increased with the concentration of $\mathrm{KOH}$, from $12.73 \%$ (P-BFS/ $\mathrm{KOH}-4 \mathrm{M})$ to $20.78 \%$ (P-BFS/KOH-8M). This indicated that the amount of hydration products in $\mathrm{P}-\mathrm{BFS} / \mathrm{KOH}-8 \mathrm{M}$ were higher than in $\mathrm{P}-\mathrm{BFS} / \mathrm{KOH}-4 \mathrm{M}$. This growth was expected, due to the increase of $\mathrm{KOH}$ content available to activate the BFS.

The microstructure of hydrated products is shown in Fig. 8(a) and (b) for P-BFS/KOH-4M, and Fig. 8(c) and (d) for P-BFS/KOH$8 \mathrm{M}$. Both presented a dense matrix with microcrystals and amorphous rounded particles. Microcrystals in P-BFS/KOH-8M were more common, presenting a twined platelet-like microstructure (Fig. 8(d)). EDS analyses were carried out to compare the composition of the cementing gel in both pastes. Gels analysed in $4 \mathrm{M}$ and $8 \mathrm{M}$ pastes contained similar $\mathrm{SiO}_{2}$ content $(21.6 \pm 2.1 \%$ vs $23.5 \pm$ $2.3 \%), \mathrm{Al}_{2} \mathrm{O}_{3}$ content $(6.8 \pm 0.8 \%$ vs $7.37 \pm 1.4 \%)$ and $\mathrm{CaO}$ content $(28.9 \pm 2.1 \%$ vs $25.3 \pm 7.9 \%)$. However, the $\mathrm{K}_{2} \mathrm{O}$ content was very different: $33.0 \pm 3.6 \%$ for $4 \mathrm{M}$ and $27.1 \pm 1.7 \%$ for $8 \mathrm{M}$. The higher percentage for the gel formed in $4 \mathrm{M} \mathrm{KOH}$ paste suggested that less gel was formed, and the main part of the potassium was incorporated into the hydration products. In this way, a part of the BFS did not react, as suggested by the low value of mass loss in thermogravimetric analysis (Table 5) and the weak strength development (Table 3). In contrast, the higher $\mathrm{KOH}$ concentration for the P-BFS/ $\mathrm{KOH}-8 \mathrm{M}$ system activated more BFS, producing more hydrates. That is why the potassium content in the formed gel was lower.

\subsection{BFS activated by $O B A$}

The effect of OBA on BFS reactivity was assessed by the mechanical strength and microstructure evolution for mortars and pastes produced with different contents of OBA (BFS replacement by OBA or OBA addition to BFS). Table 3 also summarizes the values of Rc and Rf strengths, and Figs. 5 and 6 show the behaviour of the corresponding mortars cured at $65{ }^{\circ} \mathrm{C}$ for 7 days.

The replacement series, OBA-Rpz, also showed a nonlinear strength behaviour with replacement percentage (Figs. 5 and 6). Rc increased up to $30 \%$ of OBA content $(\mathrm{Rc}=31.25 \mathrm{MPa})$ and decreased for $35 \%(\mathrm{Rc}=27.81 \mathrm{MPa})$. The minimum $\mathrm{Rc}$ value was found for $5 \%$ of OBA content $(\mathrm{Rc}=16.27 \mathrm{MPa})$. A similar trend was described for $\mathrm{Rf}$ development, in this case being $20 \%$ replacement the optimum ( $R f=6.30 \mathrm{MPa})$. Despite the lower content in BFS for OBA replacement series, the strength development was good, and strength performance for $\mathrm{z}=20-35 \%$ was higher than that found for the $\mathrm{KOH}$ series. This means that the effectiveness of OBA as an activating reagent largely surpassed $\mathrm{KOH}$. Most likely, the combined effect of potassium and calcium present in OBA makes BFS more reactive. The OBA replacement series had a similar trend to that observed for the $\mathrm{NaOH}$ series, and reached strengths that were comparable. Thus, the $12 \mathrm{M} \mathrm{NaOH}$ and OBA-Rp30 systems reached optimum strengths (31.11 and $31.25 \mathrm{MPa}$ respectively). Also, $6 \mathrm{M} \mathrm{NaOH}$ and OBA-Rp20 were similar. Fittings of compressive strength ( $\mathrm{Rc}$, in $\mathrm{MPa}$ ) versus activation solution

Table 4

Mercury intrusion porosimetry data for P-BFS/KOH-xM and P-OBA-Adx pastes.

\begin{tabular}{|c|c|c|c|c|c|}
\hline Description & Unit & $\mathrm{P}-\mathrm{BFS} / \mathrm{KOH}-4 \mathrm{M}$ & P-BFS/KOH-8M & P-OBA-Ad10 & P-OBA-Ad25 \\
\hline Mean pore diameter & $\mathrm{nm}$ & 48.20 & 22.92 & 16.74 & 11.87 \\
\hline Volume & $\mathrm{cm}^{3} / \mathrm{g}$ & 0.29 & 0.10 & 0.20 & 0.12 \\
\hline Surface area & $\mathrm{m}^{2} / \mathrm{g}$ & 4.11 & 6.43 & 17.42 & 18.35 \\
\hline Total porosity & $\%$ & 47.16 & 23.74 & 42.85 & 29.67 \\
\hline
\end{tabular}


Table 5

Thermogravimetric data for selected alkali-activated pastes.

\begin{tabular}{|c|c|c|c|c|}
\hline \multirow[t]{2}{*}{ Paste } & \multicolumn{3}{|c|}{ Mass loss (ML, in \%) in the temperature range $\left({ }^{\circ} \mathrm{C}\right)$} & \multirow[t]{2}{*}{ Total mass loss $(\%$} \\
\hline & 0-200 (ML-1) & $200-350(\mathrm{ML}-2)$ & $350-600(\mathrm{ML}-3)$ & \\
\hline $\mathrm{P}-\mathrm{BFS} / \mathrm{KOH}-4 \mathrm{M}$ & 6.11 & 4.41 & 2.21 & 12.73 \\
\hline P-BFS/KOH-8M & 11.78 & 5 & 4 & 20.78 \\
\hline P-KPH-Ad20-4M & 3.77 & 4.01 & 1.82 & 9.6 \\
\hline P-OBA-Ad20 & 5.52 & 3.3 & 2.49 & 11.31 \\
\hline P-OBA-Ad25 & 8.78 & 3.47 & 2.39 & 14.64 \\
\hline
\end{tabular}

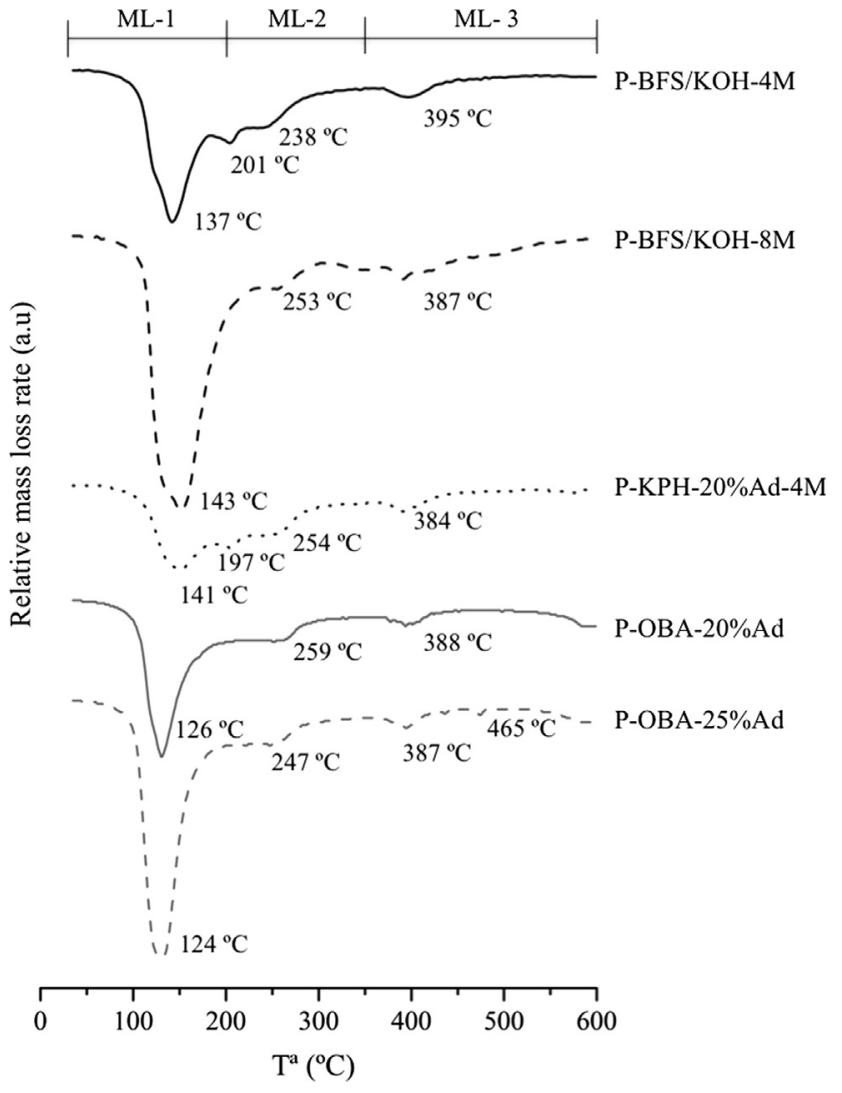

Fig. 7. Selected DTG curves for pastes P-BFS/KOH-4M, P-BFS/KOH-8M, P-KPHAd20-4M, P-OBA-Ad20 and P-OBA-Ad25.

parameter $(\mathrm{NaOH}$ concentration $[\mathrm{NaOH}]$, or OBA replacement [OBA-Rpz]) were calculated as follows by Eqs. (1) and (2):

$\mathrm{Rc}=11.592 * \mathrm{Ln}[\mathrm{NaOH}]+2.201$

$\mathrm{Rc}=21.577 * \mathrm{Ln}[\mathrm{OBA}-\mathrm{Rpz}]-40.741$

From these equations, a relationship for the equivalency between $\mathrm{NaOH}$ concentration and OBA replacement can be calculated (Fig. 9).

The addition series (BFS content was maintained constant and OBA was added in different percentages with respect to BFS), OBA-Ady, showed a continuously increasing strength up to $25 \%$ content of OBA (Figs. 5 and 6). The maximum values for Rc and Rf were found with $25 \%$ of OBA ( $\mathrm{Rc}=38.38 \mathrm{MPa}$ and $\mathrm{Rf}=7.01$ $\mathrm{MPa})$, and the minimum values were found with $5 \%$ of $\mathrm{OBA}(\mathrm{Rc}=$ 8.59 $\mathrm{MPa}$ and $\mathrm{Rf}=2.64 \mathrm{MPa}$ ). Compressive strength depended linearly on the OBA addition (OBA-Ady), as shown in Eq. (3):

$\mathrm{Rc}=1.564 *[\mathrm{OBA}-\mathrm{Ady}]+0.405$

Equivalency analysis for compressive strength revealed that Rc values using $\mathrm{NaOH}$ solutions (range from 17.57 to $31.11 \mathrm{MPa}$ ) were reached by using OBA addition percentages between $10.97 \%$ and
$19.63 \%$, according to Eq. (3). The higher OBA addition percentage produced better mortars in terms of strength. Based on the reference family mortars activated with $\mathrm{KOH}$ and $\mathrm{NaOH}$, it is clear that mortars produced with the addition of OBA, in amounts of $20 \%$ and $25 \%$, presented compressive strength values higher than those developed by the reference series, which reached their maximums in $8 \mathrm{M}$ for $\mathrm{KOH}(\mathrm{Rc}=25.56 \mathrm{MPa})$, and in $12 \mathrm{M}$ for $\mathrm{NaOH}(\mathrm{Rc}=31.11$ $\mathrm{MPa})$.

The results of MIP tests (Table 4) showed a significant reduction of porosity and mean pore diameter with the increase of OBA contents from 10 to $25 \%$. Thus, P-OBA-Ad10 paste had $42.85 \%$ total porosity and P-OBA-Ad25 had $29.67 \%$. This explained the large differences in strength (16.13 MPa vs. $38.38 \mathrm{MPa})$. Also, the lowest mean pore diameter value was found for P-OBA-Ad25 $(11.9 \mathrm{~nm})$. This means that the microstructure of the activated material became more refined with increasing OBA addition, justifying the increase of mechanical strengths in the corresponding mortars.

Comparing the series P-BFS/KOH-x with P-OBA-Ady, a significant change in the total porosity was not observed (P-BFS/KOH$8 \mathrm{M}$ vs. P-OBA-Ad25, $23.74 \%$ vs $29.67 \%$ ). However, the mechanical strengths of the corresponding mortars showed strong differences: $\mathrm{BFS} / \mathrm{KOH}-8 \mathrm{M}(\mathrm{Rc}=25.56 \mathrm{MPa}, \mathrm{Rf}=5.81 \mathrm{MPa})$ and OBA-Ad25 $(\mathrm{Rc}=$ $38.38 \mathrm{MPa}, \mathrm{Rf}=7.01 \mathrm{MPa}$ ).

The gain in strength for the OBA series could be attributed to the nature of the hydrated products. Also, the filler effect of the OBA may be taken into account: OBA was not dissolved totally in water, and consequently a filler effect (more fine particles in the mortar matrix) could play an additional role.

\subsubsection{Analysis of the filler effect}

The filler effect of the OBA was assessed considering the behaviour of the mechanical strengths of mortars produced with an inert material. Kephalite ( $\mathrm{KPH}$, andalucite) presented a similar fineness to OBA (Fig. 2). Two types of mortars, KPH-Ad20-4M (addition of $20 \% \mathrm{KPH}$ by mass respect to BFS content, and activated with $4 \mathrm{M} \mathrm{KOH}$ solution) and $\mathrm{KPH}-\mathrm{Rp} 20-4 \mathrm{M}$ (replacement of $20 \%$ BFS by $\mathrm{KPH}$, and activated with $4 \mathrm{M} \mathrm{KOH}$ solution), were tested. The strength values are summarized in Table 3 and the behaviour depicted in Fig. 10. They were analysed the values for: a) replacement (BFS/KOH-4M, KPH-Rp20-4M, OBA-Rp20) and b) addition (BFS/KOH-4M, KPH-Ad20-4M, OBA-Ad-20). The replacement series showed that the inert-containing mortar yielded $11.88 \mathrm{MPa}$, which is slightly lower than the corresponding BFS/KOH sample $(\approx 18 \%$ less strength). This means that $\mathrm{KPH}$ contributed as an inert material. The addition series showed that inert-containing mortar yielded $15.31 \mathrm{MPa}$, slightly higher than the corresponding BFS/ $\mathrm{KOH}$ sample $(\approx 5 \%)$. This behaviour suggests that, despite having the same BFS content and a larger quantity of fine particles, the filler contribution to strength development was practically negligible. Considering the filler effect as a function of the fineness (PDS), and the similarity of PDS curves for KPH and OBA (Fig. 2), it is suggested that the filler effect did not contribute significantly to the strength gain of the mortars produced with the OBA. The large strength gain observed when comparing the $\mathrm{KOH}$ activated sample and OBA activated sample in the replacing ( $\approx 79 \%$ gain) 

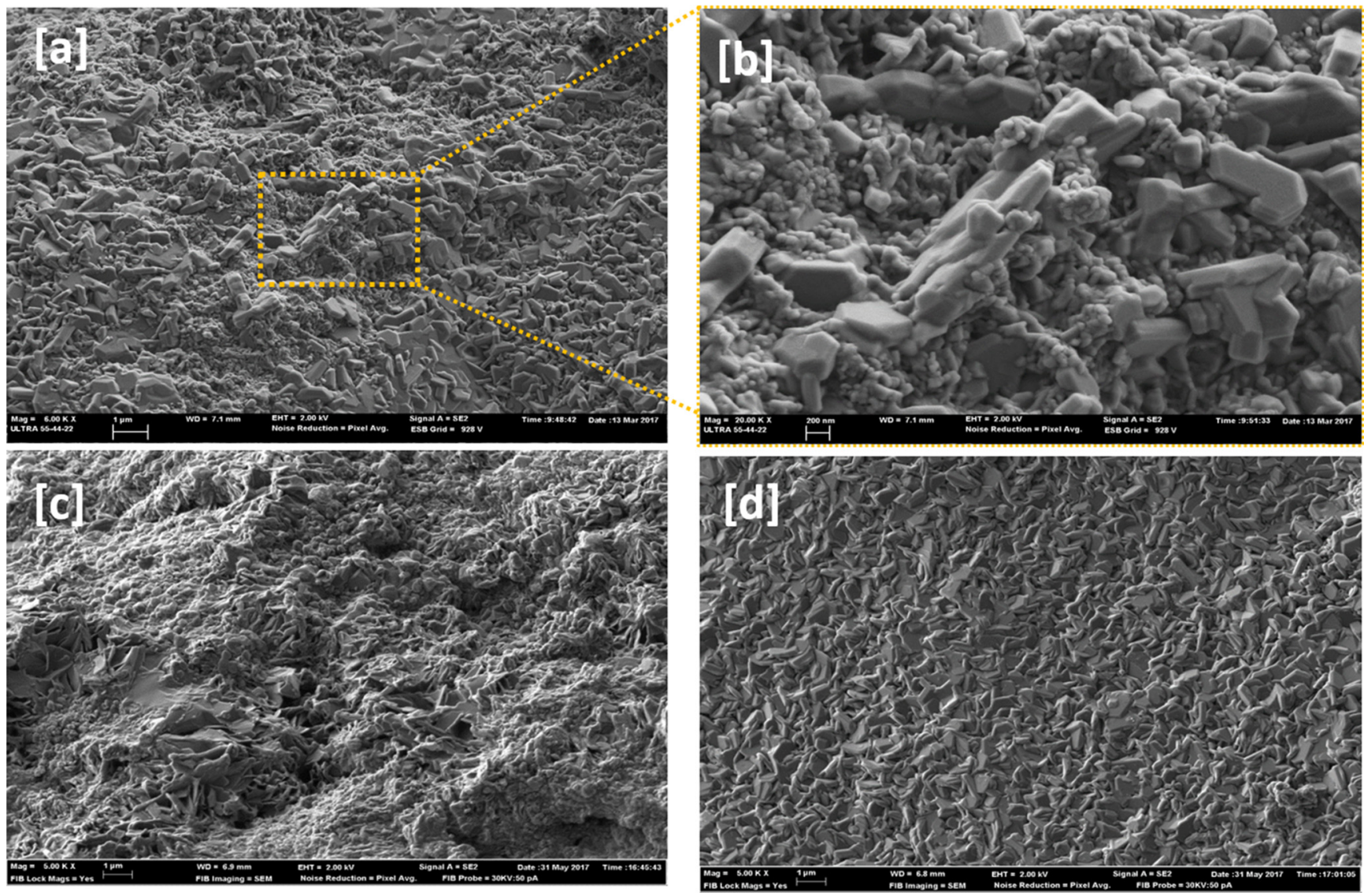

Fig. 8. FESEM micrographs of BFS pastes activated with $\mathrm{KOH}$ solution: a) General view for P-BFS/KOH-4M matrix; b) Detail from the above micrograph; c) General view for P$\mathrm{BFS} / \mathrm{KOH}-8 \mathrm{M}$; d) microcrystals in P-BFS/KOH-8M.

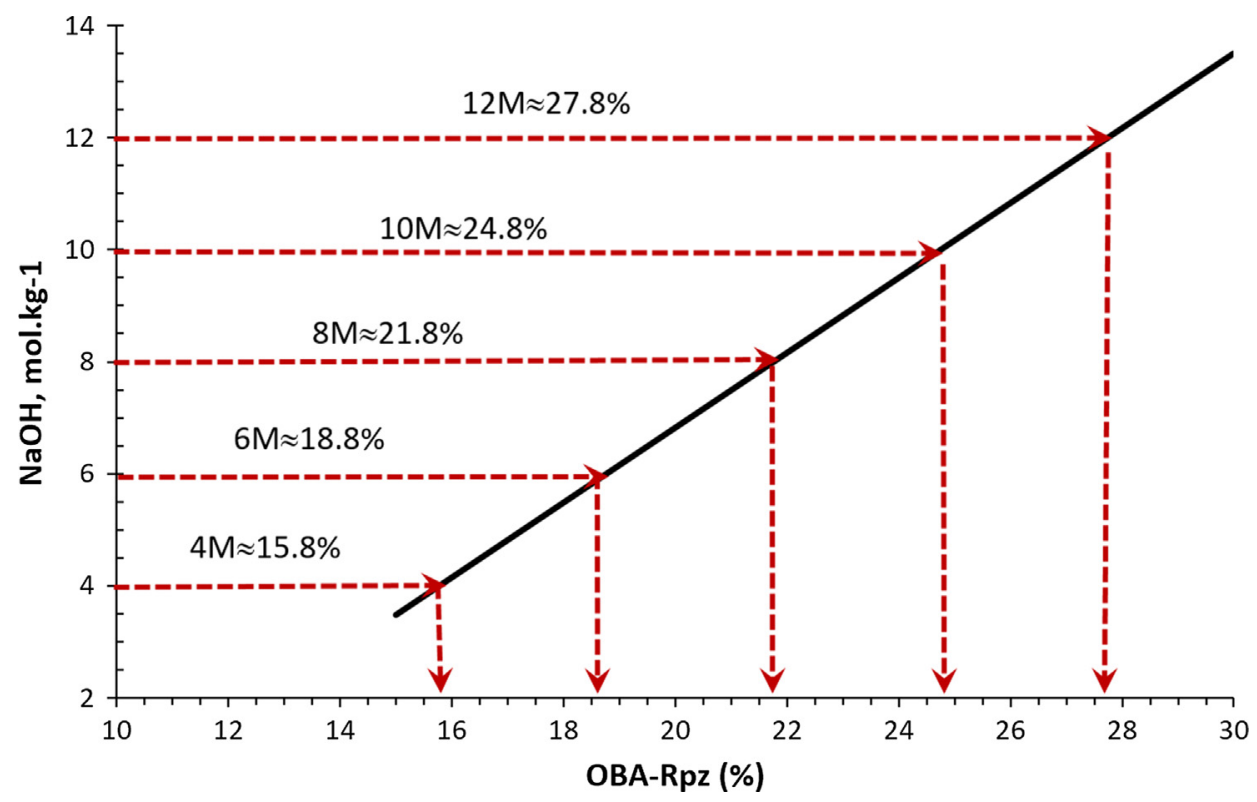

Fig. 9. Equivalences between the $\mathrm{NaOH}$ concentration and \% of OBA replacement, in BFS mortars.

and addition ( $\approx 138 \%$ gain) tests is attributed to the contribution of OBA to the hydration of BFS.

\subsubsection{Hydration products in BFS/OBA activated systems}

TG/DTG results for KPH and OBA pastes are shown in Fig. 7 and Table 5. The total mass loss for P-KPH-Ad20-4M was lower ( $\approx 25 \%$ ) than that found for P-BFS/KOH-4M, which was attributed to the dilution effect produced with the addition of the inert material. The temperature DTG peaks were very similar, when comparing curves in Fig. 7.

DTG curves for OBA containing pastes showed a large peak at $124-126^{\circ} \mathrm{C}$, which indicated that the nature and amount of 


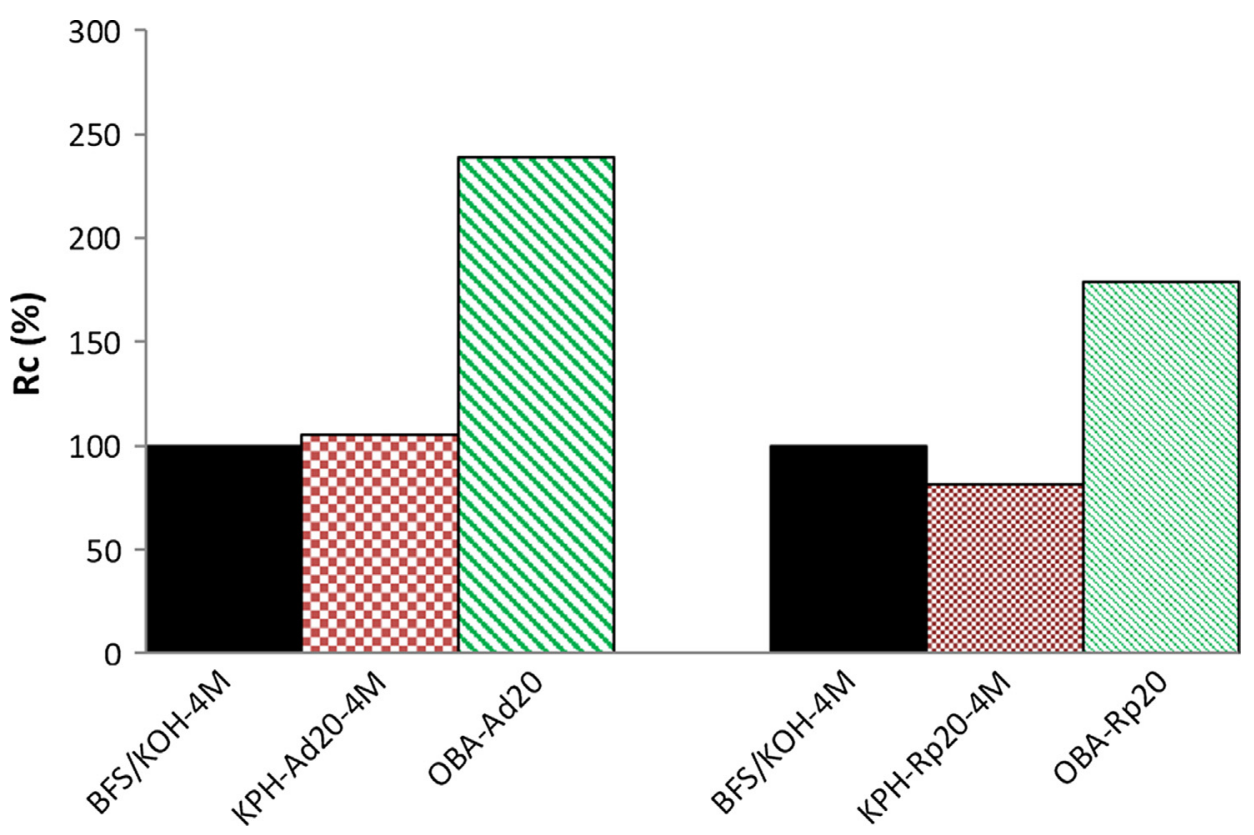

Fig. 10. Filler effect assessment from compressive strength values.

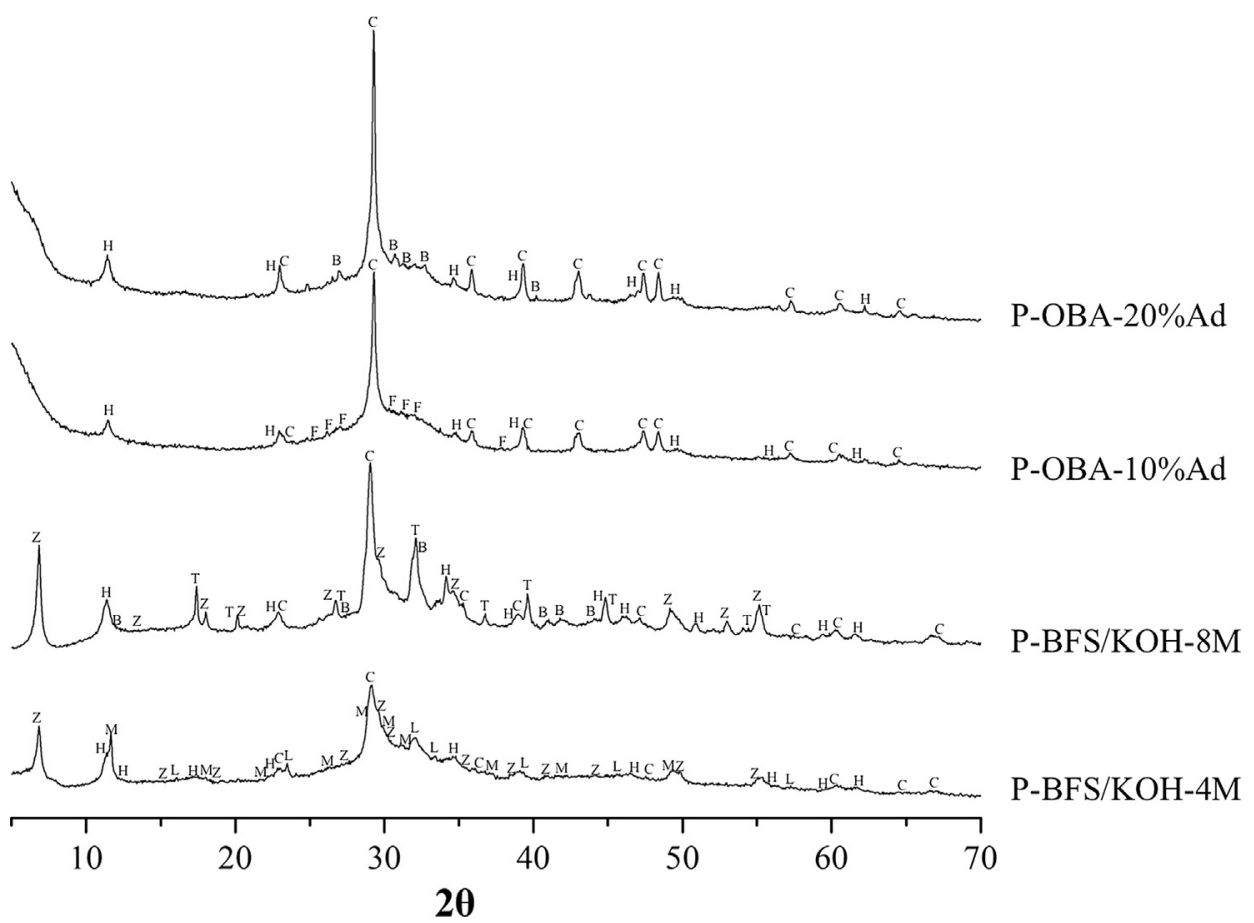

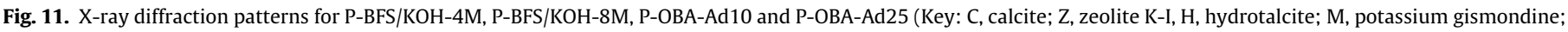
L, larnite; T, katoite; B, potassium carbonate hydrate; F, fukalite).

hydrates were slightly different than those observed in the $\mathrm{KOH}$ activated BFS-pastes. However, the total mass loss (Table 5) for the OBA containing pastes was significantly lower than that found for $\mathrm{KOH}$ pastes. For example, P-BFS/KOH-8M showed $20.73 \%$ total mass loss, while P-OBA-Ad 25 had only $14.71 \%$. This behaviour suggests that despite the lower amount of combined water, the mechanical properties and chemical nature of the hydrates formed in the activation of BFS in the presence of OBA is different than expected.

Results from XRD analyses on selected pastes are shown in Fig. 11. The differences between $\mathrm{KOH}$ and OBA activated pastes are clear. Both BFS pastes activated with $\mathrm{KOH}(4 \mathrm{M}$ and $8 \mathrm{M})$ showed calcite, hydrotalcite $\left(\mathrm{Mg}_{6} \mathrm{Al}_{2} \mathrm{CO}_{3}(\mathrm{OH})_{16} \cdot 4 \mathrm{H}_{2} \mathrm{O}\right.$, PDF card $140191)$ and $\mathrm{K}-\mathrm{I}$ zeolite $\left(\mathrm{K}_{2} \mathrm{Al}_{2} \mathrm{Si}_{2} \mathrm{O}_{8} \cdot 3.8 \mathrm{H}_{2} \mathrm{O}\right.$, PDF card 180988) as main crystalline products. Most likely, the calcite presence was because it was in the BFS composition; the rest of products were formed from the hydration processes. Additional zeolitic phases were formed in these $\mathrm{KOH}$ pastes. Potassium gismondine $\left(\mathrm{K}_{2} \mathrm{~A}_{2} \mathrm{ISi}_{2} \mathrm{O}_{8} \cdot 3 \mathrm{H}_{2} \mathrm{O}\right.$, PDF card 110188$)$ was identified in the XRD pattern of $4 \mathrm{M} \mathrm{KOH}$ activated paste and katoite $\left(\mathrm{Ca}_{3} \mathrm{Al}_{2}\left(\mathrm{SiO}_{4}\right)(\mathrm{OH})_{8}\right.$, PDF card 380368) was identified for the $8 \mathrm{M}$ activated paste. Also, in this last paste, potassium carbonate hydrate $\left(\mathrm{K}_{2} \mathrm{CO}_{3} \cdot 1.5 \mathrm{H}_{2} \mathrm{O}\right.$, PDF 
card 110655) was found, and its presence may be due to the carbonation of unreacted $\mathrm{KOH}$.

OBA containing pastes ( 10 and $25 \%$ addition of OBA to BFS) also showed calcite as the main crystalline product in the XRD patterns, due to the presence of this phase in BFS and in OBA. However, the main crystalline compound formed under the activation by OBA was hydrotalcite. No presence of katoite and K-I zeolite was observed suggesting that evolution of zeolitic structures were not developed. This behaviour is in agreement with the better mechanical strength found for OBA containing systems. In the 10\% and 25\% OBA pastes, small amounts of fukalite $\left(\mathrm{Ca}_{4} \mathrm{Si}_{2} \mathrm{O}_{6}\left(\mathrm{CO}_{3}\right)(\mathrm{OH})_{2}\right.$, PDF card 290308) and potassium carbonate hydrate, respectively, were found.

The microstructure of the hydrated products in pastes was analysed by FESEM in Fig. 12 (P-OBA-Ad10) and Fig. 13 (P-OBA-Ad25). P-OBA-Ad25 presented a more compact microstructure than $\mathrm{P}$ OBA-Ad10, and their microstructures were slightly different from the reference pastes (P-BFS/KOH-xM, see Fig. 8). Two different gels were observed in pastes with OBA: a dense one and a compact one. The morphology of the microcrystals (denser phases) was different that that observed for reference pastes, suggesting that these differences may be responsible of the different mechanical behaviour of the corresponding mortars.

The mean chemical composition values were obtained by averaging 8-10 EDS data sets (see Table 6). The $\mathrm{SiO}_{2}$ content in OBA containing pastes $(29.17 \pm 3.39$ for $10 \%$ OBA, $28.91 \pm 1.61$ for $25 \%$ OBA) was significantly higher than those found for $\mathrm{KOH}$ activated pastes. The same behaviour was found for $\mathrm{Al}_{2} \mathrm{O}_{3}$ and $\mathrm{CaO}$ contents.
The $\mathrm{CaO}$ content was significantly high, reaching values from 34 to $41 \%$, suggesting that calcium from OBA also reacted with the BFS. The $\mathrm{K}_{2} \mathrm{O}$ content was significantly lower, ranging less than a half of the percentage found in $\mathrm{KOH}$ activated pastes. All these differences indicated that the activation of BFS was more complete in the presence of OBA.

\section{Conclusions}

The ash obtained from the combustion of olive-stone biomass (OBA) was tested as an activator reagent for blast furnace slag (BFS), and compared to the effect of typical activating solutions of $\mathrm{KOH}$ and $\mathrm{NaOH}$ (in the range $4-14 \mathrm{~mol} \cdot \mathrm{kg}^{-1}$ ). The chemical composition of OBA showed high percentages of $\mathrm{K}_{2} \mathrm{O}$ and $\mathrm{CaO}$, which become interesting for preparing BFS activated systems. The effect of OBA on the strength development of BFS-based mortars was very significant for both partial replacement of BFS and addition to BFS. The compressive strength of mortars with 20-35\% replacement of BFS by OBA yielded higher values than those obtained for $\mathrm{BFS}-\mathrm{KOH}$ systems. An equivalency between $\mathrm{NaOH}$ concentration in the activating solution and OBA replacement in the activation of BFS was found (e.g., $4 \mathrm{M} \mathrm{NaOH}$ was equivalent to $15.8 \%$ OBA replacement and $8 \mathrm{M} \mathrm{NaOH}$ to $27.8 \% \mathrm{OBA}$ replacement). The addition of $25 \%$ of OBA enabled reaching a value of $38 \mathrm{MPa}$ in compressive strength. The effect of OBA on the microstructure was studied, and the main features to highlight were the reduction in the mean pore diameter in the BFS activated paste and the very limited formation of zeolitic phases.
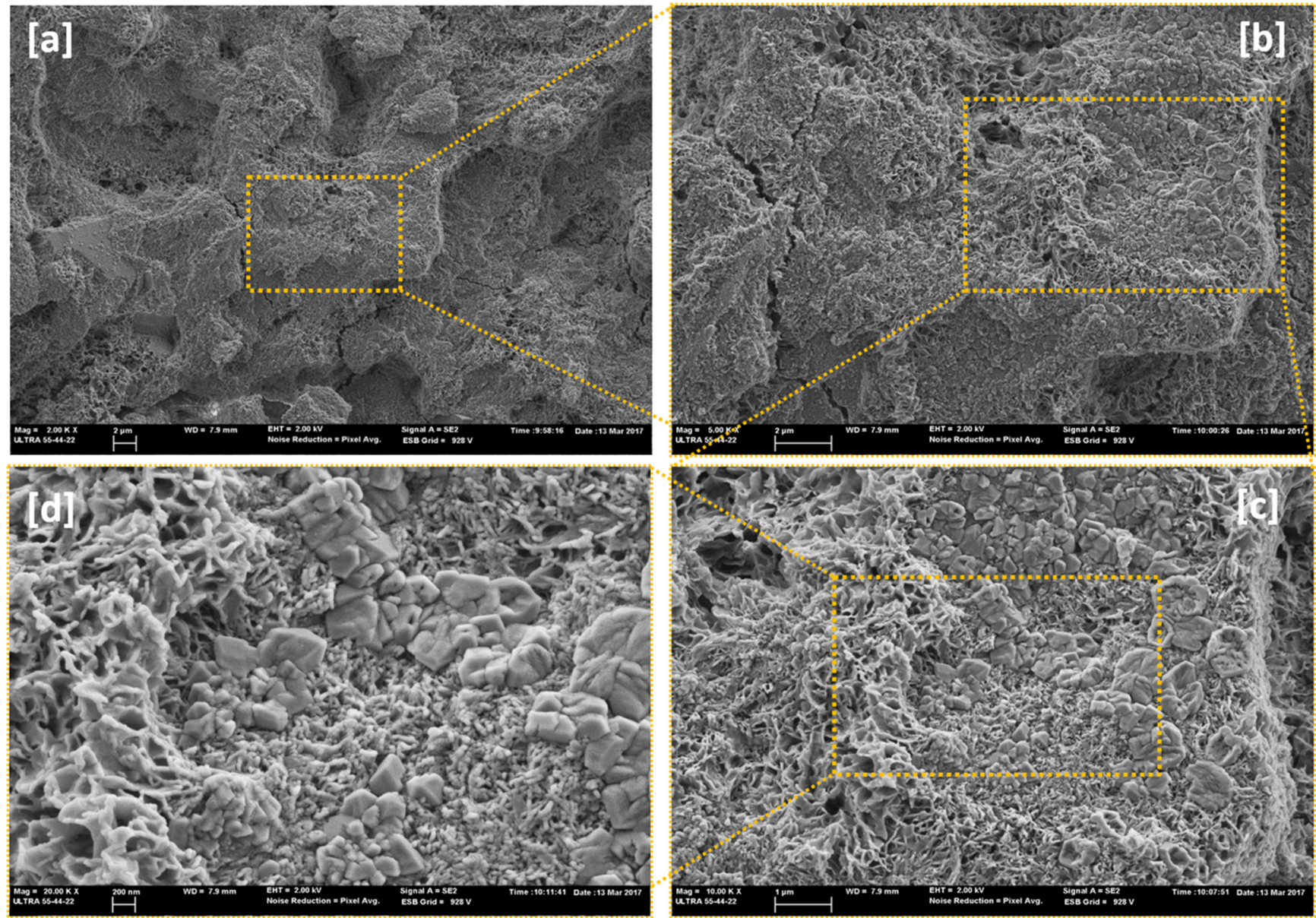

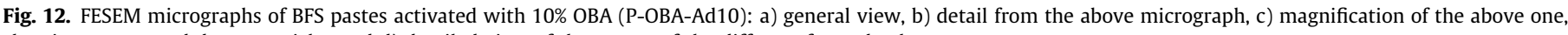
showing porous and dense particles and d) detailed view of the nature of the different formed gels 

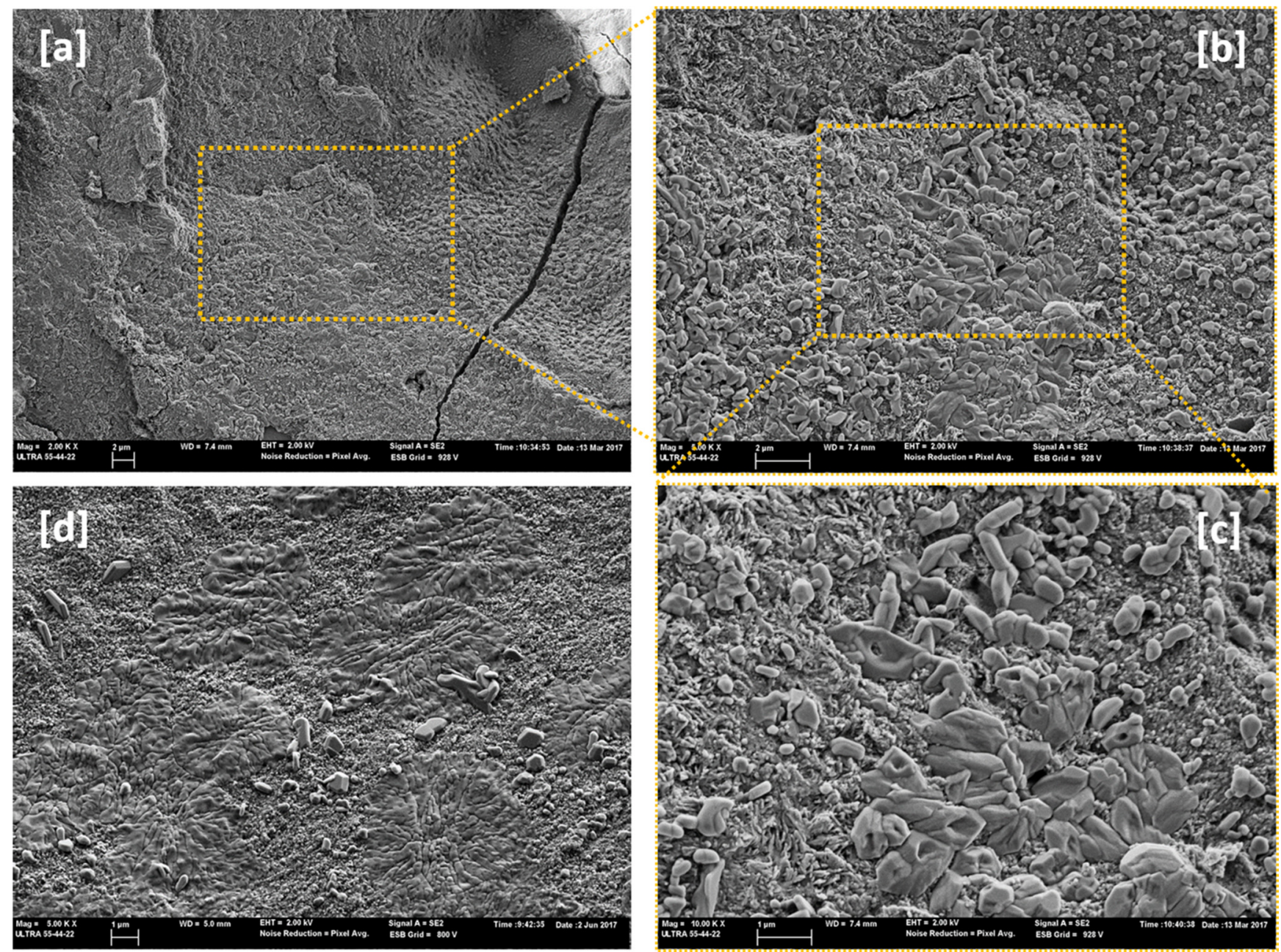

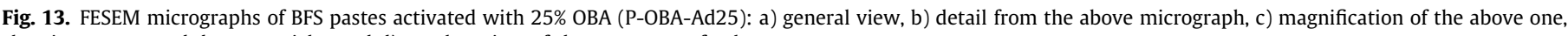
showing porous and dense particles and d) another view of the two types of gel.

Table 6

Chemical composition (EDS analysis) for studied pastes.

\begin{tabular}{|c|c|c|c|c|}
\hline Oxide (\% by mass) & P-BFS/KOH-4M & P-BFS/KOH-8M & P-OBA-Ad $10 \%$ & P-OBA-Ad25\% \\
\hline $\mathrm{Na}_{2} \mathrm{O}$ & $2.45 \pm 0.59$ & $1.64 \pm 1.07$ & $0.18 \pm 0.37$ & $0.60 \pm 0.42$ \\
\hline MgO & $3.39 \pm 0.79$ & $4.15 \pm 1.22$ & $5.27 \pm 0.64$ & $7.47 \pm 1.38$ \\
\hline $\mathrm{Al}_{2} \mathrm{O}_{3}$ & $6.76 \pm 0.80$ & $7.37 \pm 1.41$ & $8.73 \pm 1.09$ & $9.61 \pm 1.11$ \\
\hline $\mathrm{SiO}_{2}$ & $21.61 \pm 2.14$ & $23.50 \pm 2.35$ & $29.17 \pm 3.39$ & $28.91 \pm 1.61$ \\
\hline $\mathrm{SO}_{3}$ & $0.92 \pm 1.14$ & $5.27 \pm 2.45$ & $3.93 \pm 1.20$ & $4.07 \pm 1.28$ \\
\hline $\mathrm{K}_{2} \mathrm{O}$ & $32.99 \pm 3.64$ & $27.16 \pm 1.70$ & $11.23 \pm 2.64$ & $14.91 \pm 3.27$ \\
\hline $\mathrm{CaO}$ & $28.94 \pm 2.08$ & $25.28 \pm 7.93$ & $41.19 \pm 3.03$ & $34.04 \pm 1.54$ \\
\hline
\end{tabular}

This study demonstrated the viability of using OBA in the activation of BFS and the reduction in the consumption of commercial chemical reagents for AAM preparation. This allows a more sustainable AAM.

\section{Conflict of interest}

\section{None.}

\section{Acknowledgements}

The authors are grateful to CAPES for the scholarship. Thanks are also given to Electron Microscopy Service of the Universitat
Politècnica de València, the GeocelPlus-UPV project and Almazara Candela - Elche, Spain.

\section{References}

[1] L.K. Turner, F.G. Collins, Carbon dioxide equivalent (CO2-e) emissions: a comparison between geopolymer and OPC cement concrete, Constr. Build Mater. $43 \quad$ (2013) 125-130, https://doi.org/10.1016/ j.conbuildmat.2013.01.023.

[2] F. Pacheco-Torgal, J. Labrincha, C. Leonelli, A. Palomo, P. Chindaprasit, Handbook of Alkali-Activated Cements, Mortars and Concretes, Woodhead Publishing - Elsevier, 2014.

[3] J. Davidovits, Geopolymer Chemistry and Application, fourth ed., Institut Géopolymère, France, 2015.

[4] A. Palomo, P. Krivenko, I. Garcia-Lodeiro, E. Kavalerova, O. Maltseva, A. Fernández-Jiménez, A review on alkaline activation: new analytical 
perspectives, Mater. Constr. 64 (2014) e022, https://doi.org/10.3989/ mc.2014.00314.

[5] A. Fernández -Jiménez, F. Puertas, Influence of the activator concentration on the kinetics of the alkaline activation process of a blast furnace slag, Mater. Constr. 47 (1997) 31-42.

[6] A. Fernández-Jiménez, J.G. Palomo, F. Puertas, Alkali-activated slag mortars: mechanical strength behaviour, Cem. Concr. Res. 29 (1999) 1313-1321, https://doi.org/10.1016/S0008-8846(99)00154-4.

[7] F. Pelisser, E.L. Guerrino, M. Menger, M.D. Michel, J.A. Labrincha, Micromechanical characterization of metakaolin-based geopolymers, Constr. Build. Mater. 49 (2013) 547-553, https://doi.org/10.1016/ j.conbuildmat.2013.08.081.

[8] U. Rattanasak, P. Chindaprasirt, Influence of $\mathrm{NaOH}$ solution on the synthesis of fly ash geopolymer, Miner. Eng. 22 (2009) 1073-1078, https://doi.org/10.1016/ j.mineng.2009.03.022.

[9] J. Temuujin, A. Riessen, K.J.D. MacKenzie, Preparation and characterisation of fly ash based geopolymer mortars, Constr. Build. Mater. 24 (2010) 1906-1910, https://doi.org/10.1016/j.conbuildmat.2010.04.012.

[10] M.M. Tashima, J.L. Akasaki, V.N. Castaldelli, L. Soriano, J. Monzó, J. Payá, M.V. Borrachero, New geopolymeric binder based on fluid catalytic cracking catalyst residue (FCC), Mater. Lett. 80 (2012) 50-52, https://doi.org/10.1016/ j.matlet.2012.04.051.

[11] L. Reig, M.M. Tashima, M.V. Borrachero, J. Monzó, C.R. Cheeseman, J. Payá, Properties and microstructure of alkali-activated red clay brick waste, Constr. Build. Mater. 43 (2013) 98-106, https://doi.org/10.1016/ j.conbuildmat.2013.01.031.

[12] R.H. Geraldo, C.M. Ouellet-Plamondon, E.A.D. Muianga, G. Camarini, Alkaliactivated binder containing wastes: a study with rice husk ash and red ceramic, Cerâmica 63 (2017) 44-51, https://doi.org/10.1590/036669132017633652057.

[13] R.A.A.B. Santa, A.M. Bernardin, Geopolymer synthetized from bottom coal ash and calcined paper sludge, J. Clean. Prod. 57 (2013) 302-307, https://doi.org/ 10.1016/j.jclepro.2013.05.017.

[14] J.C.B. Moraes, M.M. Tashima, J.L. Akasaki, J.L.P. Melges, J. Monzó, M.V. Borrachero, L. Soriano, J. Payá, Increasing the sustainability of alkaliactivated binders: the use of sugar cane straw ash (SCSA), Constr. Build. Mater. $124 \quad$ (2016) 148-154, https://doi.org/10.1016/ j.conbuildmat.2016.07.090.

[15] X. Gao, Q.L. Yu, A. Lazaro, H.J.H. Brouwers, Investigation on a green olivine nano-silica source based activator in alkali activated slag-fly ash blends: reaction kinetics, gel structure and carbon footprint, Cem. Concr. Res. 100 (2017) 129-139, https://doi.org/10.1016/j.cemconres.2017.06.007.

[16] A. Mellado, C. Catalán, N. Bouzón, M.V. Borrachero, J. Monzó, J. Payá, Carbon footprint of geopolymeric mortar: study of the contribution of the alkaline activating solution and assessment of an alternative route, RSC Adv. 4 (2014) 23846-23852, https://doi.org/10.1039/c4ra03375b.

[17] J.M. Mejía, R. Mejía de Gutiérrez, F. Puertas, Rice husk ash as a source of silica in alkali-activated fly ash and granulated blast furnace slag systems, Mater. Constr. 63 (2013) 361-375, https://doi.org/10.3989/mc.2013.04712.

[18] N. Bouzón, J. Payá, M.V. Borrachero, L. Soriano, M.M. Tashima, J. Monzó, Refluxed rice husk ash/NaOH suspension for preparing alkali activated binders, Mater. Lett. 115 (2014) 72-74, https://doi.org/10.1016/ j.matlet.2013.10.001.

[19] R.H. Geraldo, L.F.R. Fernandes, G. Camarini, Water treatment sludge and rice husk ash to sustainable geopolymer production, J. Clean. Prod. 149 (2017) 146-155, https://doi.org/10.1016/j.jclepro.2017.02.076.

[20] J.M. Mejía, R. Mejía de Gutiérrez, C. Montes, Rice husk ash and diatomaceous earth as a source of silica to fabricate a geopolymeric binary binder, J. Clean. Prod. 118 (2016) 33-139, https://doi.org/10.1016/j.jclepro.2016.01.057.

[21] A. Fernández-Jiménez, N. Cristelo, T. Miranda, A. Palomo, Sustainable alkali activated materials: precursor and activator derived from industrial wastes, J. Clean. Prod. 162 (2017) 1200-1209, https://doi.org/10.1016/j. jclepro.2017.06.151.

[22] A. Font, L. Soriano, J.C.B. Moraes, M.M. Tashima, J. Monzó, M.V. Borrachero, J. Payá, A $100 \%$ waste-based alkali-activated material by using olive-stone biomass ash (OBA) and blast furnace slag (BFS), Mater. Lett. 203 (2017) 46-49, https://doi.org/10.1016/j.matlet.2017.05.129.

[23] A. Peys, H. Rahier, Y. Pontikes, Potassium-rich biomass ashes as activators in metakaolin-based inorganic polymers, Appl. Clay Sci. 119 (2016) 401-409, https://doi.org/10.1016/j.clay.2015.11.003.

[24] A. Roig, M.L. Cayuela, M.A. Sánchez-Monedero, An overview on olive mill wastes and their valorisation methods, Waste Manage. 26 (2006) 960-969, https://doi.org/10.1016/j.wasman.2005.07.024.

[25] Junta de Andalucía, Potencial energético de los subproductos de la industria olivarera en Andalucía, Secretaría General del Medio Rural y la Producción Ecológica, 2010. agriculturaypesca/portal/export/sites/
default/comun/galerias/galeriaDescargas/cap/servicio-estadisticas/Estudios-einformes/desarrollo-rural-sost/IND_OLIVAR_V1_CC.pdf.

[26] E. Romero, M. Quirantes, R. Nogales, Characterization of biomass ashes produced at different temperatures from olive-oil-industry and greenhouse vegetable wastes, Fuel 208 (2017) 1-9, https://doi.org/10.1016/ j.fuel.2017.06.133.

[27] R.M.L. Medeiros, F. Villa, D.F. Silva, L.R.C. Júlio, Destinação e reaproveitamento de subprodutos da extração olivícola, Sci. Agrar. Parana. 15 (2016) 100-108, https://doi.org/10.18188/1983-1471/sap.v15n2p100-108 (in Portuguese).

[28] A.G. Vlyssides, M. Loizides, P.K. Karlis, Integrated strategic approach for reusing olive oil extraction by-products, J. Clean. Prod. 12 (2004) 603-611, https://doi.org/10.1016/S0959-6526(03)00078-7.

[29] S. Souilem, A. El-Abbassi, H. Kiai, A. Hafidi, S. Sayadi, C.M. Galanakis, Olive oil production sector environmental effects and sustainability challenges, in: C.M. Galanakis (Ed.), Olive Mill Waste: Recent Advance for Sustainable Management, 2017, https://doi.org/10.1016/B978-0-12-805314-0.00001-7.

[30] J.A. Alburquerque, J. Gonzálvez, D. García, J. Cegarra, Agrochemical characterisation of 'alperujo', a solid by-product of the two-phase centrifugation method for olive oil extraction, Bioresour. Technol. 91 (2004) 195-200, https://doi.org/10.1016/S0960-8524(03)00177-9.

[31] A.E. Hanandeh, Energy recovery alternatives for the sustainable management of olive oil industry waste in Australia: life cycle assessment, J. Clean. Prod. 91 (2015) 78-88, https://doi.org/10.1016/j.jclepro.2014.12.005.

[32] A.C. Caputo, F. Scacchia, P.M. Pelagagge, Disposal of by-products in olive oil industry: waste-to-energy solutions, Appl. Therm. Eng. 23 (2003) 197-214 https://doi.org/10.1016/S1359-4311(02)00173-4.

[33] N.G. Nair, J. Markham, Recycling Solid Waste from the Olive Oil Extraction, Rural Industries Research and Development Corporation - Australian Government, 2008. https://rirdc.infoservices.com.au/downloads/08-16.

[34] IOC-International Olive Oil Council, 2017, World Olive Oil Figures. (http:// www.internationaloliveoil.org/estaticos/view/131-world-olive-oil-figures? lang=en_US).

[35] D. Vamvuka, D. Zografos, Predicting the behaviour of ash from agricultural wastes during combustion, Fuel 83 (2004) 2051-2057, https://doi.org/ 10.1016/j.fuel.2004.04.012.

[36] N.M. Al-Akhras, K.M. Al-Akhras, M.F. Attom, Performance of olive waste ash concrete exposed to elevated temperatures, Fire Saf. J. 44 (2009) 370-375, https://doi.org/10.1016/j.firesaf.2008.08.006.

[37] N.M. Al-Akhras, M.Y. Abdulwahid, Utilisation of olive waste ash in mortar mixes, Struct. Concr. 11 (2010) 221-228, https://doi.org/10.1680/ stco.2010.11.4.221.

[38] N.M. Al-Akhras, Performance of olive waste ash concrete exposed to alkalisilica reaction, Struct. Concr. 13 (2012) 221-226, https://doi.org/ 10.1002/suco.201100058.

[39] A. Eisa, Properties of concrete incorporating recycled post-consumer environmental wastes, Int. J. Concr. Struct. Mater. 8 (2014) 251-258, https:// doi.org/10.1007/s40069-013-0065-9.

[40] M. Cruz-Yusta, J. Morales Mármol, L. Sánchez, Use of olive biomass fly ash in the preparation of environmentally friendly mortars, Environ. Sci. Technol. 45 (2011) 6991-6996, https://doi.org/10.1021/es200968a.

[41] S.V. Vassilev, D. Baxter, L.K. Andersen, C.G. Vassileva, An overview of the chemical composition of biomass, Fuel 89 (2010) 913-933, https://doi.org/ 10.1016/j.fuel.2009.10.022.

[42] J. Cuenca, J. Rodríguez, M. Martín-Morales, Z. Sánchez-Roldán, M. Zamorano, Effects of olive residue biomass fly ash as filler in self-compacting concrete Constr. Build. Mater. 40 (2013) 702-709, https://doi.org/10.1016/ j.conbuildmat.2012.09.101.

[43] A. Demirbas, Combustion characteristics of different biomass fuels, Prog. Energy Combust. Sci. 30 (2004) 219-230, https://doi.org/10.1016/j. pecs.2003.10.004.

[44] P.E. Miles, Alkali Deposits Found in Biomass Power Plants - A Preliminary Investigation of Their Extent and Nature, National Renewable Energy Laboratory (Colorado, USA), 1995. https://www.nrel.gov/docs/legosti/fy96/ 8142v1.pdf.

[45] UNE-EN 196-1, Methods of Testing Cement - Part 1: Determination of Strength, AENOR, 2005.

[46] X. Chen, S. Wu, J. Zhou, Influence of porosity on compressive and tensile strength of cement mortar, Constr. Build. Mater. 40 (2013) 869-874, https:// doi.org/10.1016/j.conbuildmat.2012.11.072.

[47] A.A. Abdel-Gawwad, S. Abd El-Aleem, Effect of reactive magnesium on properties of alkali activated slag cement pastes, Ceramics - Silikáty 59 (2015) 37-47, https://doi.org/10.1061/(ASCE)MT.1943-5533.0001207.

[48] O.G. Rivera, W.R. Long, C.A. Weiss Jr., R.D. Moser, B.A. Williams, K. TorresCancel, E.R. Gore, P.G. Allison, Effect of elevated temperature on alkaliactivated geopolymeric binders compared to Portland cement-based binders, Cem. Concr. Res. 90 (2016) 43-51, https://doi.org/10.1016/j. cemconres.2016.09.013. 